Tetrahedron report number 552

\title{
Recent chemistry of benzocyclobutenes
}

\author{
Goverdhan Mehta ${ }^{\mathrm{a}, *}$ and Sambasivarao Kotha, ${ }^{\mathrm{b}, *}$ \\ ${ }^{a}$ Department of Organic Chemistry, Indian Institute of Science, Bangalore, 500 012, India \\ ${ }^{\mathrm{b}}$ Department of Chemistry, Indian Institute of Technology, Powai, Mumbai, 400 076, India
}

1. Introduction 626

1.1. Scope of the review 626

$\begin{array}{ll}\text { 1.2. Structure and reactivity aspects } & 626\end{array}$

2. Preparation of benzocyclobutenes $\quad 627$

2.1. Elimination method $\quad 627$

2.2. Parham cyclization $\quad 628$

2.3. Photochemical approaches 629

2.4. Extrusion reactions 630

2.5. Diels-Alder reaction based approaches 631

2.6. Benzyne intermediates 631

2.7. [2+2+2] Cycloaddition approaches 631

2.8. Ring expansion methods 632

2.9. Allene intermediates 633

2.10. Miscellaneous methods $\quad 633$

3. Reactions of benzocyclobutenes 634

3.1. Cyclobutane ring cleavage reactions 634

3.2. Electrophilic aromatic substitution reactions 636

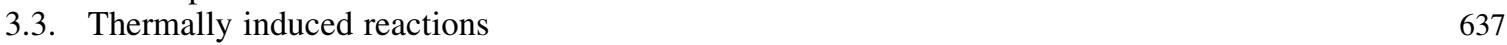

3.4. Photochemical reactions 638

3.5. Oxidation and reduction reactions $\quad 639$

3.6. Ring adjustment reactions 630

3.7. Reactive intermediates involving BCBs 641

3.8. Reactions via benzocyclobutadiene 641

3.9. Miscellaneous reactions of BCBs 642

4. Reactions of benzocyclobutenedione (BCBD) 643

5. Applications of BCBs in synthesis $\quad 644$

5.1. Alkaloid synthesis $\quad 644$

$\begin{array}{ll}\text { 5.2. Steroid synthesis } & 646\end{array}$

$\begin{array}{ll}\text { 5.3. Anthracycline and related quinone synthesis } & 649\end{array}$

5.4. Derivatization of fullerenes 650

$\begin{array}{ll}\text { 5.5. Cyclophane synthesis } & 651\end{array}$

5.6. Miscellaneous applications of BCBs 651

6. Synthesis of natural products containing a BCB unit 653

$\begin{array}{ll}\text { 7. Concluding remarks } & 654\end{array}$

\footnotetext{
* Corresponding authors. Tel.: +91-80-360-2367; fax: +91-80-360-0936; e-mail: gm@ orgchem.iisc.ernet.in; tel.: +91-22-576-7152; fax: +91-22-572-3480; e-mail: srk@chem.iitb.ernet.in
} 

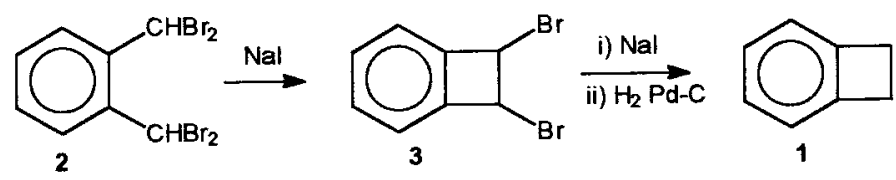

Scheme 1.

\section{Introduction}

The bicyclo[4.2.0]octa-1,3,5-triene 1, often referred to (incorrectly) in the literature as benzocyclobutene (BCB), and its derivatives have a long and interesting history. ${ }^{1} \mathrm{BCB}$ 1 has also been named as benzocyclobutane, cardene, benzocyclobutene-1,2-dihydro, cyclobutabenzene and generically as cyclobutarene in the chemical literature. In 1909, Finkelstein reported the first authenticated preparation of BCB through 1,4-elimination in $\alpha, \alpha, \alpha^{\prime}, \alpha^{\prime}$-tetrabromo-o-xylene 2 with sodium iodide. ${ }^{2}$ The work formed part of his doctoral thesis and was overlooked for decades as it was not published until 1959. ${ }^{3}$ In 1956, however, Cava and Napier ${ }^{4}$ prepared the parent BCB 1 from the dibromide 3 by catalytic hydrogenation and confirmed the earlier work of Finkelstein (Scheme 1).

$\mathrm{BCB}$ derivatives represent a unique class of reactive molecules because of the thermodynamic stability associated with the aromatic system and the kinetic reactivity of the strained cyclobutene ring. They are useful building blocks because of their ability to isomerize to $o$-xylylenes (e.g. 4) upon thermal activation (Scheme 2). The ease with which $o$-xylylenes participate in inter- and intramolecular Diels-Alder reactions with various dienophiles makes BCBs useful as building blocks in the synthesis of complex polycyclic compounds. Jensen and Coleman were the first to carry out thermolysis of trans-1,2-diphenylbenzocyclobutene 5 in the presence of maleic anhydride to give the tetralin derivative 7 and suggested the intermediacy of $o$-xylylene (or o-quinodimethane) 6 (Scheme 3). ${ }^{5}$ The driving force for these reactions is aromaticity recovery and Huisgen demonstrated that they generally proceeded in a stereoselective manner. ${ }^{6}$ The thermolytic ring opening of BCBs occurs in a conrotatory manner in conformity with the predictions based on orbital symmetry rules. ${ }^{7}$ Methods for the generation of $o$-xylylenes and their synthetic utility has been reviewed. ${ }^{8}$

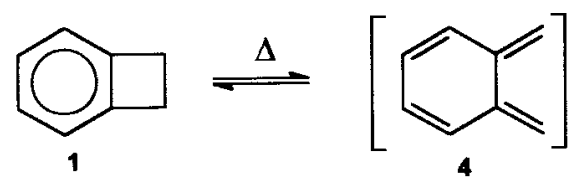

Over the years, BCBs have emerged as versatile chemical entities and their molecular structure, structural diversity, syntheses and chemical reactivity continue to engage the attention of organic chemists. More recently, BCBs have served as important building blocks for natural product syntheses and for new polymers and advanced materials. These developments and the future potential of BCBs have provided an impetus to present an overview of their chemistry and form the subject matter of this report.

\subsection{Scope of the review}

This review will cover aspects related to the synthesis, reactions and applications of BCBs and provide an overview of the existing literature with appropriate emphasis on recent examples. Various synthetic targets such as steroids, alkaloids, anthracyclines, organic derivatives of $\mathrm{C}_{60}$ and cyclophanes using BCBs as intermediates will be discussed. Although the recent examples are given more emphasis, earlier efforts are also included in order to provide a balanced overview of the topic. Several theoretically interesting molecules related to BCBs (e.g. extended biphenylene derivatives) are not included as these are discussed in a monograph $^{9}$ and a recent review. ${ }^{10}$ For a comprehensive coverage of specific uses of BCBs in synthesis, the reader is referred to specialized review articles (e.g. $o$-xylylenes, ${ }^{8}$ and BCBs in steroid ${ }^{11}$ and polymer synthesis ${ }^{12}$ ).

\subsection{Structure and reactivity aspects}

The total energy of BCB $\mathbf{1}$ has been calculated employing different levels of theory and the values vary from 303.85332 to $308.57922 \mathrm{kcal} / \mathrm{mol} .{ }^{13}$ The structures of the ground states of $\mathbf{1}$ and $\mathbf{4}$ have been studied by ab initio SCF calculations and these confirmed that the open form 4 has pronounced single-bond/double-bond alteration in the hexagonal ring, whereas the bicyclic form $\mathbf{1}$ has a benzenoid structure. ${ }^{14,15}$ The calculated energies indicate that BCB $\mathbf{1}$ is more stable than $o$-xylylene 4 by $55 \mathrm{KJ} \mathrm{mol}^{-1}$. The microwave spectra of BCB and its deuterated species have been determined ${ }^{16}$ and the $\Delta I$ values suggest that only four hydrogen atoms are located out of the molecular skeletal plane of 1. A series of BCBs with increasing distortion have been computationally studied through Hartree-Fock calculations the $6-31 \mathrm{G}^{*}$ level and the $\pi$ electrons showing increasing stability relative to those in the corresponding

Scheme 2.
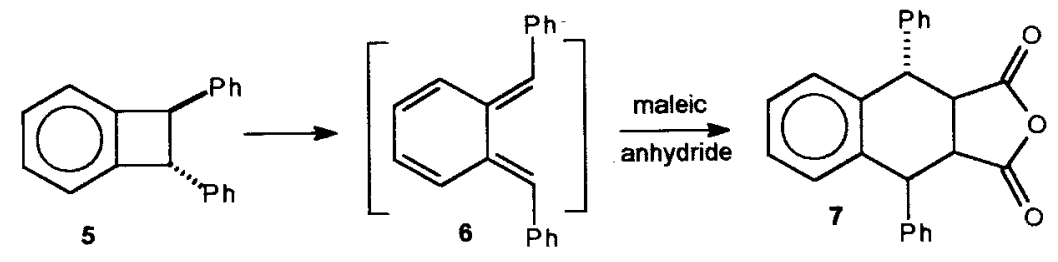


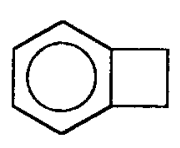

ref $19 a$<smiles>Brc1ccc(Br)c2c1CC2</smiles>

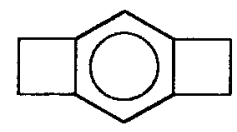

ref $19 a$<smiles>BrC1c2ccccc2C1Br</smiles>

ref $19 b$
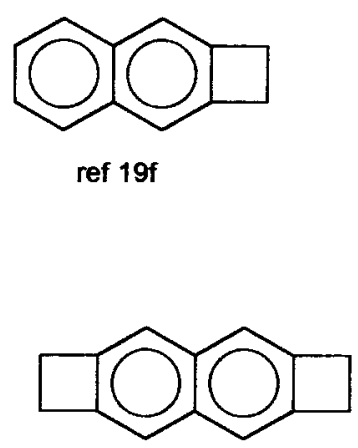

ref $19 \mathrm{~h}$<smiles>O=c1c(=O)c2ccccc12</smiles>

ref $19 \mathrm{c}$

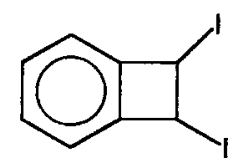

ref 19d

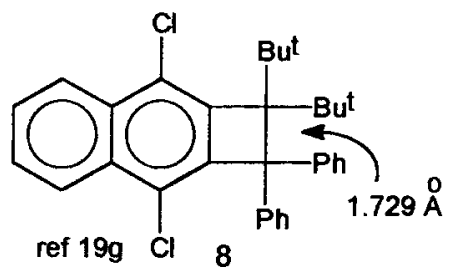<smiles>O=Cc1cccc2c1C1(O)c3ccccc3CCC21</smiles>

ref $19 i$

Figure 1. Some examples of BCB derivatives whose X-ray structures have been determined.

methyl-substituted benzene systems. This result is in accord with the photoelectron spectroscopic data and the notion that $\pi$ electrons in benzene disfavor the symmetric structure. ${ }^{17}$ EPR spectral evidence on 3,6-dimethyl-1,2,4,5-tetrahydrobenzobiscyclobutene and 3,4,5,6-tetramethyl-BCB shows that the $\Psi_{\mathrm{A}}$ MO lies above the $\Psi_{\mathrm{S}} \mathrm{MO}$ and this observation is rationalized in terms of rehybridization of the arene carbon atoms imposed by ring strain. ${ }^{18} \mathrm{X}$-Ray crystallographic analysis of $\mathrm{BCB}$ at $-170^{\circ} \mathrm{C}$ shows an unusual structure and the bonds in the benzene ring adjacent to the annelated ring are shortened. Some other BCB derivatives the X-ray structures of which have been studied are tabulated in Fig. $1 .^{19}$ An extremely long $\mathrm{C}-\mathrm{C}$ bond $(1.729 \AA)$ has been observed in (-)-1,1-di-t-butyl-2,2diphenyl-3,8-dichlorocyclobuta[b]naphthalene $\mathbf{8}$, and this is amongst the longest $\mathrm{C}-\mathrm{C}$ bonds encountered to date. ${ }^{19 \mathrm{~g}}$

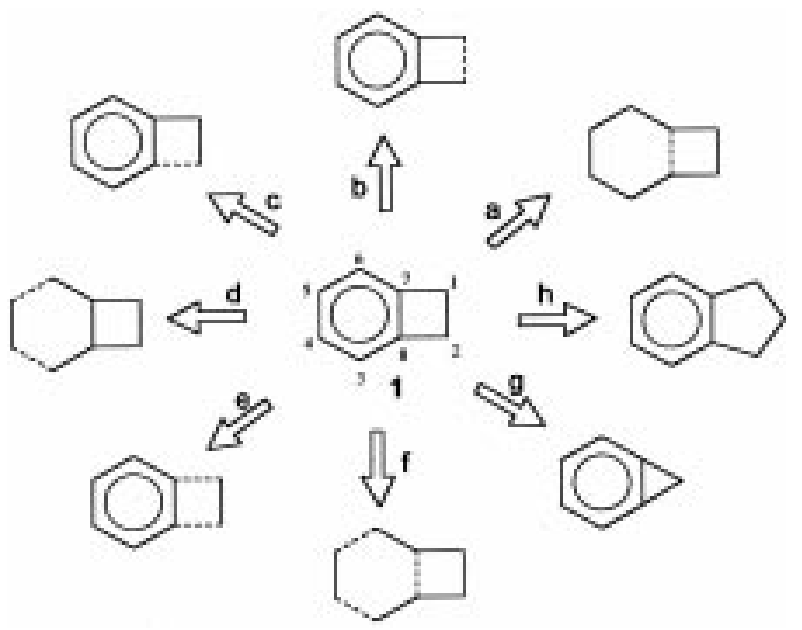

Figure 2. Various retrosynthetic approaches to BCB ring system.

\section{Preparation of benzocyclobutenes}

Despite its reported preparation in $1909,{ }^{2}$ interest in BCB lay dormant for a long time. During the late 1950s, through the pioneering efforts of Cava and co-workers, several BCB derivatives became readily available for synthetic exploration. Subsequently, several groups became interested in BCBs and this resulted in diverse applications of these systems. Presently, several methods are available for the preparation of $\mathrm{BCB}$ derivatives and each of these have their own strength and limitation with regard to ease of preparation, availability of starting materials and adaptability to functionalization. Retrosynthetic approaches involving various $\mathrm{C}-\mathrm{C}$ bond connectivity through which the BCB ring system can be constructed are shown in Fig. 2. These approaches are based on single-bond $(\mathrm{a}-\mathrm{c})$, twobond (d, e), three-bond (f) disconnection and ring adjustment reactions (g, h) (Fig. 2). Most of these approaches (b, $\mathrm{c}, \mathrm{e}, \mathrm{g}, \mathrm{h}$ ) employ pre-formed benzene derivatives as starting materials. In the case of the two-bond disconnection approaches $(\mathrm{d}, \mathrm{e})$ either benzene or cyclobutane derivatives may be used. In the three-bond disconnection approach (f), however, both benzene and cyclobutane rings are formed simultaneously. Ring adjustment approaches involve either ring-contraction $(\mathrm{h})$ or ring-expansion $(\mathrm{g})$ tactics.

\subsection{Elimination method}

1,4-Elimination from suitably functionalized benzene derivatives offers the most convenient way to access BCBs and the original Finkelstein method, ${ }^{1,3}$ as well as Cava and co-workers' preparation of the parent 1 from $\alpha, \alpha, \alpha^{\prime}, \alpha^{\prime}$-tetrabromo-o-xylene 2 followed this route. ${ }^{4} \mathrm{~A}$ later modification has enabled large scale preparation of the parent $\mathrm{BCB}$ via two step 1,4-elimination and reductive dehalogenation. ${ }^{20}$

Polysubstituted trichloromethylbenzenes, when warmed 


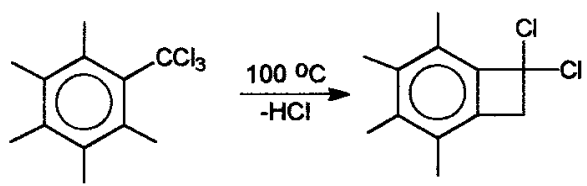

Scheme 4.

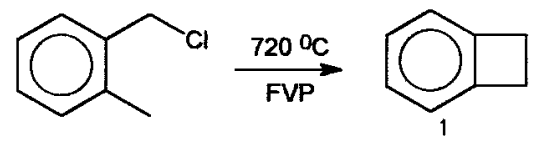

Scheme 5.

above their melting point, lose $\mathrm{HCl}$ to give 1,1-dichlorobenzocyclobutenes (Scheme 4). ${ }^{21}$ This method has been extended and improved for the large scale preparation of BCB 1 under flash vacuum pyrolysis (FVP) (Scheme $5){ }^{22-25}$ An interesting extension of this simple pyrolytic approach is the preparation of a pyridine analogue of BCB (Scheme 6). ${ }^{26}$ The ready availability of starting materials, good yield and the stability of the four-membered ring under FVP conditions makes this pyrolytic route competitive with other synthetic methods for accessing a variety of highly functionalized BCBs. This procedure, however, could not deliver highly strained systems such as tricyclobutabenzene 9 from the commercially available 2,4,6-tris(chloromethyl)-mesitylene $\mathbf{1 0}$ during FVP conditions and only hexaradialene 11 (60\%) was formed (Scheme 7). ${ }^{27 a}$ The direction of the ring closure during 1,4-elimination is not always predictable and the tetrachloro-methylnaphthalene derivative 12 on FVP furnished cyclophane based BCB 13 instead of the expected 14 as shown in Scheme $8 .^{27 b}$ Another interesting route to $\mathrm{BCBs}$ is through fluoride ion mediated 1,4-elimination in $\alpha, \alpha^{\prime}$-dialkyl-o-[(trimethyl-

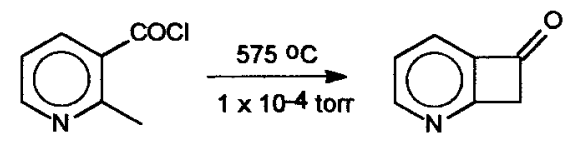

Scheme 6.

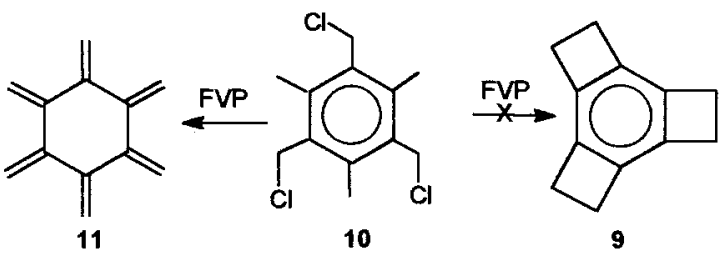

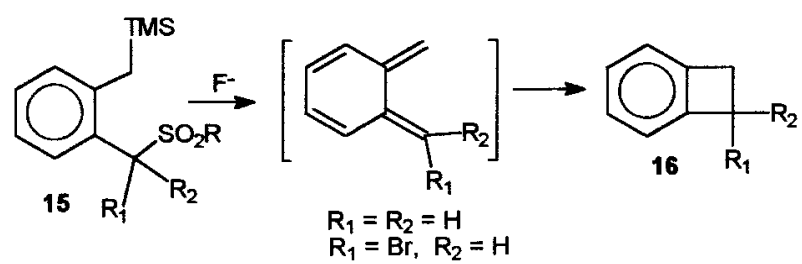

Scheme 9.

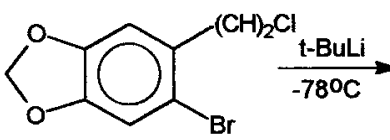

17

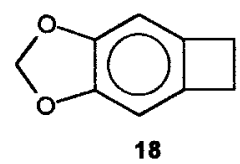

18
Scheme 10.

silyl)-methyl]benzyl- $p$-tolyl sulphones $\mathbf{1 5}$ to give $\alpha, \alpha^{\prime}$ dialkylbenzocyclobutenes 16 (Scheme 9). ${ }^{28}$

\subsection{Parham cyclization}

A simple method of general applicability for the preparation of BCBs involves intramolecular displacement via aryl anions (Parham cyclization). For example, the $o$-bromo- $\beta$ phenethyl chloride $\mathbf{1 7}$ on halogen-metal exchange gave the BCB derivative 18 in greater than $90 \%$ yield (Scheme 10). ${ }^{29}$ The methodology can be conveniently applied to the preparation of substituted BCB derivatives (e.g. 19, 20 and 21). ${ }^{30}$ The metalation-intramolecular displacement strategy has been adapted by Buchwald et al for the synthesis of 23 from 22 (Scheme 11). ${ }^{31}$

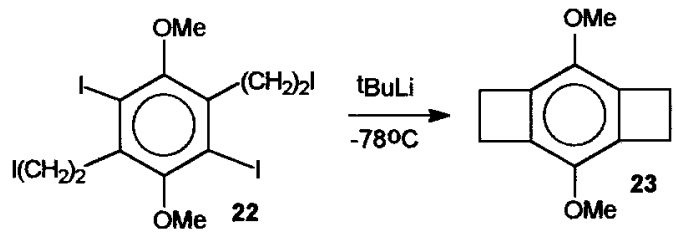

Scheme 11.
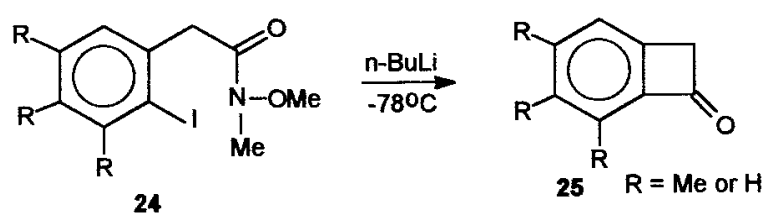

Scheme 12.

Scheme 7.

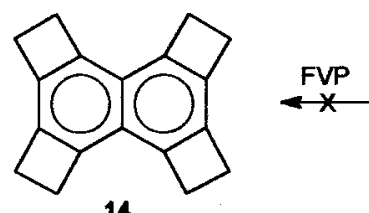

14<smiles>Cc1c(CCl)c(CCl)c(C)c2c(C)c(CCl)c(CCl)c(C)c12</smiles>

12

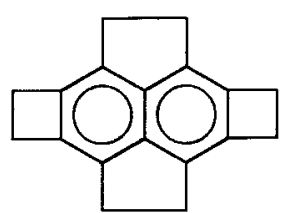

13

Scheme 8. 


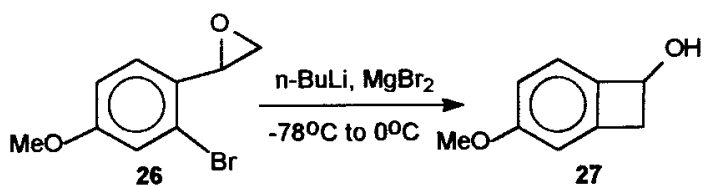

Scheme 13.

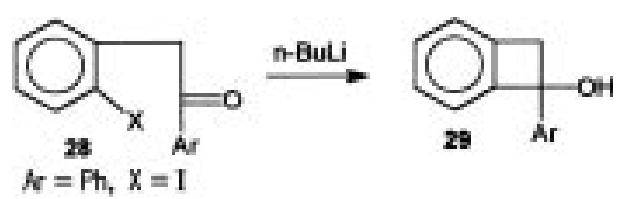

Scheme 14.

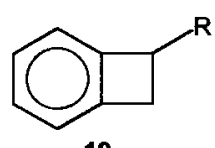

19
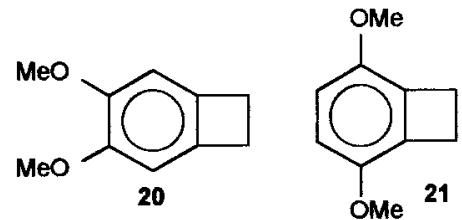

Lithium-iodine exchange-initiated cyclizations of $o$-iodo$N$-methoxy- $N$-methyl phenylacetamides $\mathbf{2 4}$ provide a simple and efficient route to the benzocyclobutenones 25 (Scheme 12). ${ }^{32}$ A slight variation of the above strategy involves treatment of the $o$-bromostyreneoxide $\mathbf{2 6}$ with $n$-BuLi to generate the BCB ring system 27 (Scheme 13). ${ }^{33}$ Lithium-halogen exchange with $n$-BuLi has been achieved in 28 even in the presence of a carbonyl group to provide an entry into 1-arylbenzocyclobutenols 29 (Scheme 14). ${ }^{34}$

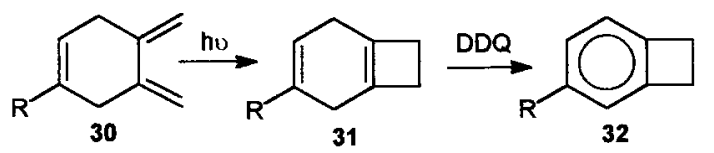

Scheme 15 .

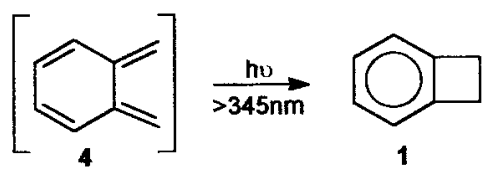

Scheme 16.

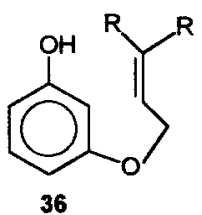

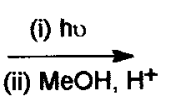

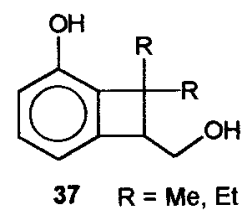

Scheme 18.

\subsection{Photochemical approaches}

Both inter- and intramolecular [2+2] photocycloadditionbased approaches have been employed for the synthesis of BCBs. For example, the diene 30, readily undergoes an intramolecular $[2+2]$ photocycloaddition reaction to generate the bicyclic system $\mathbf{3 1}$ which on further oxidation with DDQ gives the BCB derivative 32 (Scheme 15). ${ }^{35}$ Irradiation of $4(\lambda>345 \mathrm{~nm})$ at $77 \mathrm{~K}$ resulted in the formation of BCB 1 (Scheme 16). ${ }^{36}$ Nishimura and co-workers prepared dihydrocyclobuta[e]pyrene $\mathbf{3 5}$ starting from the bis-styrene derivative 34, via 33 employing an intramolecular [2+2] photocycloaddition as a key step (Scheme 17) ${ }^{37}$ Another interesting approach to substituted BCBs is through intramolecular $[2+2]$ photocycloaddition in 3-alkylphenols 36 followed by hydrolysis to yield functionalized benzocyclobutene derivatives 37 (Scheme 18). ${ }^{38}$

Intermolecular [2+2] photocycloaddition between $\beta$-methoxynaphthalene 38 and acrylonitrile furnished a tricyclic compound which upon base treatment gave the naphthocyclobutene derivatives $\mathbf{3 9}$ and $\mathbf{4 0}$ (Scheme 19). ${ }^{39}$ Oda and co-workers have reported the synthesis of 3,6dioxygenated $\mathrm{BCB}$ derivatives such as $\mathbf{4 1}$ using [2+2] photocycloaddition as a key step (Scheme 20). ${ }^{40}$

Intramolecular [2+2] photocycloaddition via a photo-enolization strategy has been employed for the preparation of various $\mathrm{BCB}$ derivatives. For example, the highly functionalized BCB derivatives $\mathbf{4 4}$ were obtained by the irradiation of $o$-alkyl substituted aromatic aldehydes or ketones $\mathbf{4 2}$, which can undergo photo-enolization via a photochemical [1,5]-hydrogen shift to $\mathbf{4 3}$ followed by intramolecular cycloaddition (Scheme 21). ${ }^{41}$ Irradiation of $o$-alkylphenyl 1,3-diketones $\mathbf{4 5}$ gave the benzocyclobutenols $\mathbf{4 6}$ via a Norrish-type photochemical reaction and these aldol intermediates underwent thermal retro-aldol cleavage to yield the benzocyclobutenones 47 (Scheme 22). ${ }^{41}$

The photochemically induced Wolff rearrangement has proved to be an excellent method for the preparation of $\mathrm{BCB}$ derivatives- by a ring contraction protocol- which are otherwise difficult to prepare. Thus, the $\alpha$-diazoindanones 48 undergo a ring contraction reaction under a

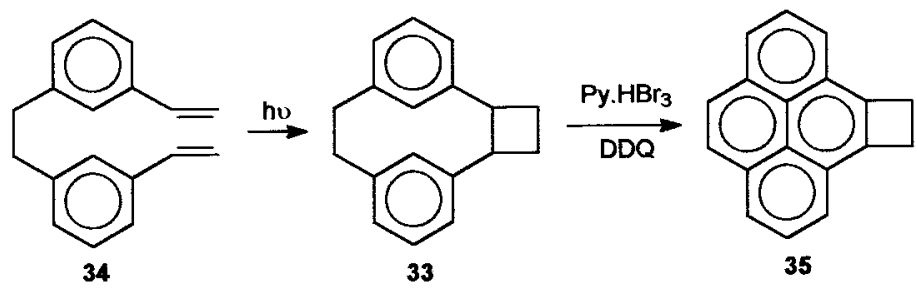




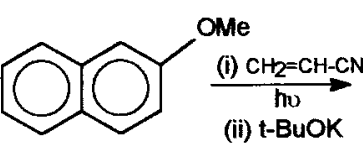

38<smiles>N#CC1Cc2c1ccc1ccccc21</smiles>

Scheme 19.<smiles>O=C1C=CC(=O)C2CCC12</smiles><smiles>C=CC1CC2C(=O)C3CCCC3C(=O)C12</smiles>

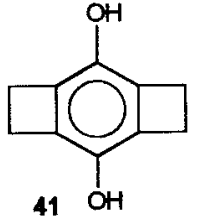

41 OH

Scheme 20 .

suitable irradiation regime to give the benzocyclobutenecarboxylic acids 49 (Scheme 23). ${ }^{42}$ This photochemical ring contraction method allows a great variety of BCB carboxylic acids to be prepared. Interestingly, the diazoketone 50, under photochemical conditions, gave only the undesired ring-opened products presumably via the benzocylobutene intermediate 51. Wolff rearrangement under thermal conditions formed 51, however, without any complications (Scheme 24). ${ }^{43}$ It was claimed that this was the first example of the formation of a strained ring system via uncatalysed thermal Wolff rearrangement.

Photodecarbonylation of 2-indanone derivatives has proved to be a useful route to benzocyclobutene-1,2-dione $\mathbf{5 2}$ (Scheme 25). ${ }^{44}$ The preparation of trans-1,2-diphenylbenzocyclobutene $\mathbf{5}$ is possible via a decarbonylation route (Scheme 26). ${ }^{45}$

\subsection{Extrusion reactions}

Several approaches towards BCB 1, employing a thermally induced extrusion reaction as the key step, have been explored and these are summarized in Scheme 27. ${ }^{46}$ Thus, the tellurophene $\mathbf{5 3}$ on FVP gave BCB 1 in $70 \%$ yield. Similarly, 3-isochromanone $\mathbf{5 4}$ and the sulfone $\mathbf{5 5}$ gave $\mathbf{1}$ by extrusion of $\mathrm{CO}_{2}$ and $\mathrm{SO}_{2}$, respectively. Thermal extrusion of sulfur dioxide from 2,5-dihydrobenzothiophene-2,2dioxides finds many applications in BCB chemistry. This<smiles>[R1][PH]=C(CC)[C@@H]([R2]C(=O)c1ccccc1C)CC</smiles><smiles>O=C(O)C1Cc2ccccc21</smiles>

Scheme 23.<smiles>N#CC1C(=O)c2ccccc2C1=O</smiles><smiles>O=C(O)C1C(=O)c2ccccc21</smiles>

Scheme 24.

reaction presumably occurs via the ring closure of thermally generated $o$-quinodimethane intermediates. Since sulphones can be readily alkylated, ${ }^{47}$ several polycyclic molecules may be prepared by adapting this technology and trapping the $o$-xylylene intermediates using an intramolecular DielsAlder reaction. ${ }^{48}$

$\mathrm{BCBs}$ with oxygenated substituents on the aryl ring can also be efficiently prepared by an extension of this $\mathrm{SO}_{2}$ extrusion methodology. When the trisulphone $\mathbf{5 7}$ was subjected to FVP conditions, however, hexaradialene $\mathbf{1 1}$ was obtained

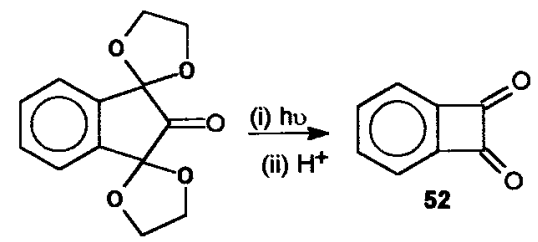

Scheme 25.<smiles>c1ccc(C2c3ccccc3C2c2ccccc2)cc1</smiles>

Scheme 21.

Scheme 26.

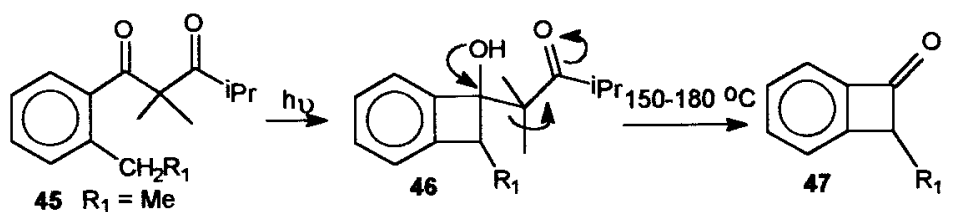




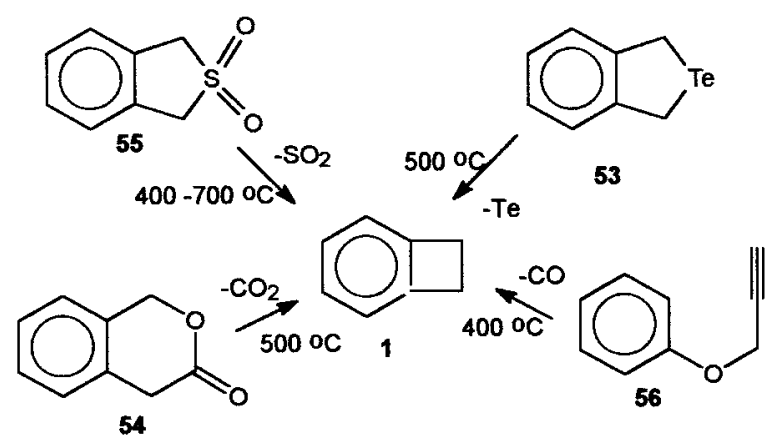

Scheme 27.

instead of the targeted tricyclobutabenzene 9 (Scheme 28). ${ }^{49}$ An interesting thermal route to BCB 1 is via the pyrolysis of phenyl propargyl ether 56 involving the extrusion of $\mathrm{CO}$ (Scheme 27).

\subsection{Diels-Alder reaction based approaches}

The synthesis of fluorinated $\mathrm{BCB}$ derivatives has been reported through the dehydrogenation of the bicyclo[4.2.0] octane system, obtained by a Diels-Alder reaction between butadiene and cyclobutene (Scheme 29). ${ }^{50} \mathrm{~A}$ similar procedure was adopted to prepare the more embellished 3,6-dimethyl-4,5-dicarbomethoxy-benzocyclobutene 58 (Scheme 30). This methodology which involves aromatization of compounds with fused cyclobutene rings seems to be well suited for condensed polycyclic aromatic compounds containing multiple fused cyclobutane rings. Milder reaction conditions used here allow the preparation of the highly strained tricyclobutabenzene $\mathbf{9}$, which is not readily accessible by other methods (vide supra) (Scheme $31){ }^{5}{ }^{5}$ Diels-Alder reaction of 3-chloro-3-cyclobutene-1,2dione 59 with 1,3-butadiene derivatives followed by oxidation gave benzocyclobutenediones 52 (Scheme 32). ${ }^{52}$

\subsection{Benzyne intermediates}

Conceptually, the synthesis of BCBs from aromatic precursors can be envisaged via [2+2] cycloadditions between a benzyne intermediate and an alkene and this approach has found much favor for the synthesis of these compounds. ${ }^{53} \mathrm{In}$ order to circumvent the use of diazonium salts as benzyne precursors, a metal-halogen exchange process has been employed in both the inter- and intramolecular modes to generate aryne intermediates. Suzuki and co-workers have reported a high yield synthesis of the benzocylobutenone $\mathbf{6 2}$ involving [2+2] cycloaddition of the ketene silyl acetals $\mathbf{6 1}$ and the aryne generated from ortho-haloaryl triflates 60 (Scheme 33). ${ }^{54}$ An intramolecular version of this aryne<smiles></smiles>

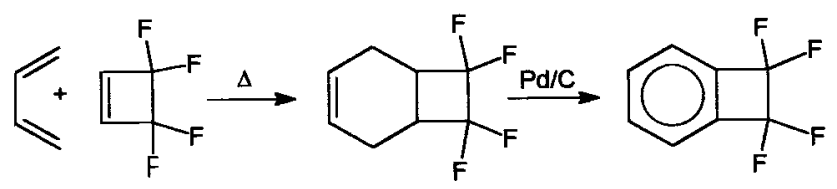

Scheme 29.

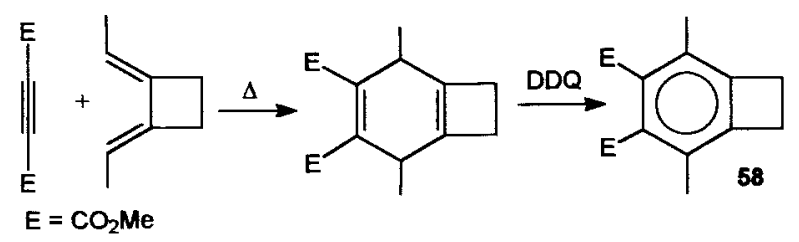

Scheme 30.

route has been used extensively by Kametani's group in preparing precursors for natural product syntheses. Treatment of the nitrile 63 with sodium amide gave the BCB derivative 64 (Scheme 34). The cyano group in the BCB 64 can be manipulated into a variety of functionalities for further appending the dienophile portion. ${ }^{55}$

\section{7. $[2+2+2]$ Cycloaddition approaches}

Vollhardt and his co-workers have pioneered a novel methodology for the synthesis of silyl substituted BCB derivatives which involves the cyclotrimerization of bis(trimethylsilyl)acetylene (BTMSA) with 1,5-hexadiyne in the presence of a catalytic amount of $\mathrm{C}_{\mathrm{p}} \mathrm{Co}(\mathrm{CO})_{2}$ (Scheme 35). ${ }^{56}$ In this method, the six-membered ring is constructed via a cobalt catalysed cyclization in which the fourmembered ring arises through the appropriate choice of the diyne substrate. The presence of the bulky TMS group in BTMSA helps to prevent alkyne self-trimerization. The advantage of this method is that the silyl groups provide a good handle for the introduction of various substituents in the benzene ring through electrophilic aromatic substitutions. In the course of preparing novel polyurethanes bicapped with a BCB moiety, 4-(benzocyclobutenyl)methanol 66 was prepared by Farona et al from the suitably protected monoalkyne $\mathbf{6 5}$ and 1,5-hexadiyne (Scheme 36). ${ }^{57}$ Recently, this methodology has been used for the

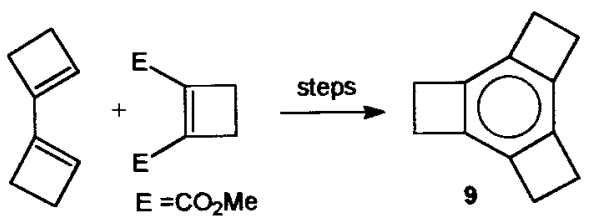

Scheme 31.
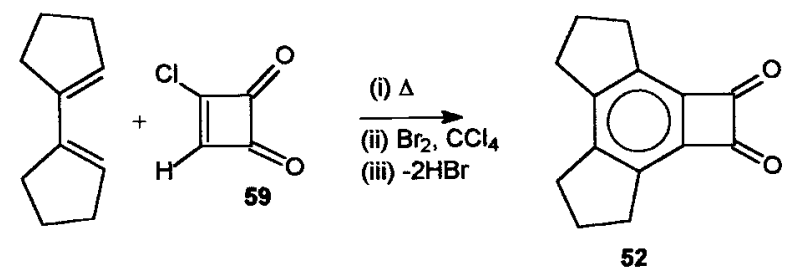

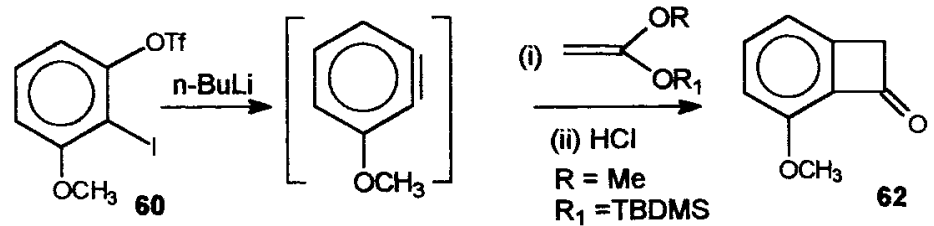

Scheme 33.
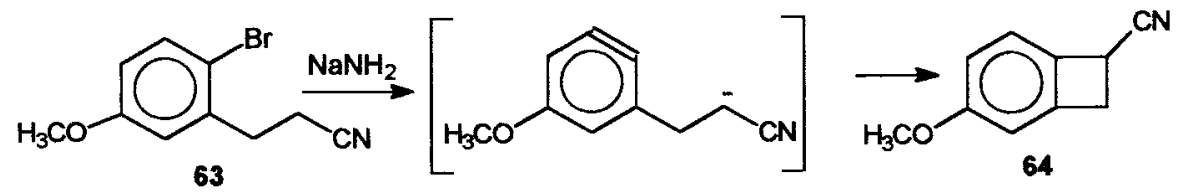

Scheme 34.
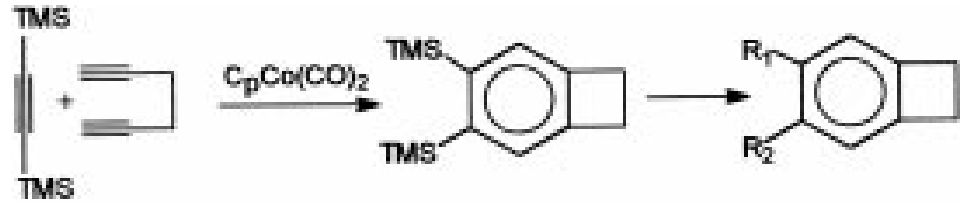

Scheme 35.

improved preparation of cyclopropa[4.5]benzocyclobutene 67 (rocketene) (Scheme 37). ${ }^{58}$

\subsection{Ring expansion methods}

BCBs have been prepared from benzocyclopropene-related substrates through ring expansion. For example, the reaction of $1 H$-cyclopropa $[b]$ naphthalene $\mathbf{6 8}$ with tris-(acetonitrile)tricarbonylchromium affords cyclobutanaphthalenone 69 in $57 \%$ yield (Scheme 38). ${ }^{59}$ This reaction proceeds through oxidative addition of the metal to the cyclopropene ring followed by $\mathrm{CO}$ insertion into the $\mathrm{C}-\mathrm{Ar}-\mathrm{Cr}$ bond and reductive elimination of the metal. Formation of a 1,1dihalobenzocyclobutene $\mathbf{7 0}$ has been observed during the reaction between benzocyclopropene and the dihalocarbene (Scheme 39). ${ }^{60}$ Since benzocyclopropene derivatives are difficult to prepare, this method may not be useful from a preparative point of view. Another sequence involving dihalocarbene intermediates and leading to $\mathrm{BCB}$ derivatives is shown in Scheme $40 .{ }^{61}$ In a related sequence,

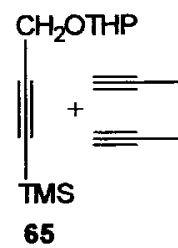<smiles>CS(=O)(=O)c1cc2c(cc1CO)CC2</smiles><smiles>OCc1ccc2c(c1)CC2</smiles>

Scheme 36.<smiles>C#CCCC(C)C(=O)OCc1cc2c(cc1N(CC(C)C)C(=O)OCc1ccccc1)CC2</smiles>

$(65 \%)$

Scheme 37.

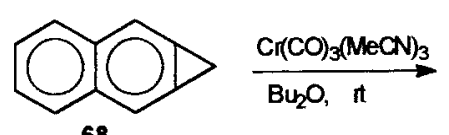

68

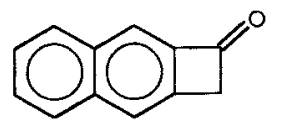

69

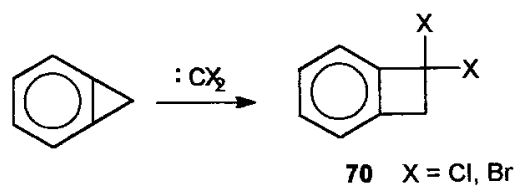




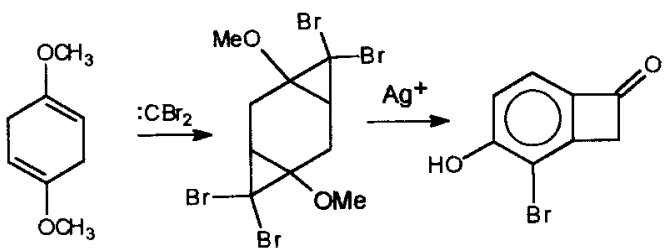

Scheme 40.

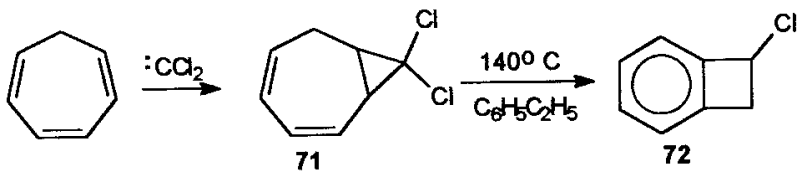

Scheme 41.

1-chlorobenzocyclobutene $\mathbf{7 2}$ was prepared from cycloheptatriene through its dihalocarbene adduct $\mathbf{7 1}$ and further rearrangement (Scheme 41). ${ }^{62}$

\subsection{Allene intermediates}

Recently, ring expansion of 3-alkylidene-4-allenylcyclobutenones $\mathbf{7 4}$ has been shown to provide a route to highly functionalized BCB derivatives $\mathbf{7 5}$. The starting allenyl substituted alkylidenecyclobutenes originate from dimethylsquarate 73 (Scheme 42). ${ }^{63}$ Another route via $6 \pi$-electron cyclization of $o$-diallenyl-arenes and -heteroarenes for the synthesis of the BCB derivatives $\mathbf{7 7}$ has been reported by Toda and co-workers involving the thermal cyclization of the enediynediol 76 (Scheme 43). ${ }^{64}$ 1,2-Diphenylnaphtho[b]cyclobutene $\mathbf{7 9}$ has been prepared from $o$-bis $(\alpha$-acetoxypropargyl)benzene derivatives $\mathbf{7 8}$ through $\mathrm{SmI}_{2}$ mediated coupling in the presence of a $\operatorname{Pd}(0)$ catalyst and involving an $o$-diallenylarene intermediate (Scheme 44). ${ }^{65}$

\subsection{Miscellaneous methods}

Cyclodimerization of polyhalogenated 2-phenyl- and 2-pentachlorophenyl-substituted butenynes $\mathbf{8 0}$ under thermal conditions furnishes the bicyclo[4.2.0]octane derivative which can be further hydrolysed/aromatized to the benzocyclobutenones 81 (Scheme 45). ${ }^{66}$ An apparently general and regioselective synthesis of substituted benzocyclobutenediones $\mathbf{8 4}$ has been reported via palladiumcatalysed coupling of a variety of 4-chlorocyclobutenones 82 with the tributylstannylcyclobutenone derivative $\mathbf{8 3}$ followed by hydrolysis (Scheme 46). ${ }^{67}$ Some of the BCB derivatives prepared by this route are not accessible by other

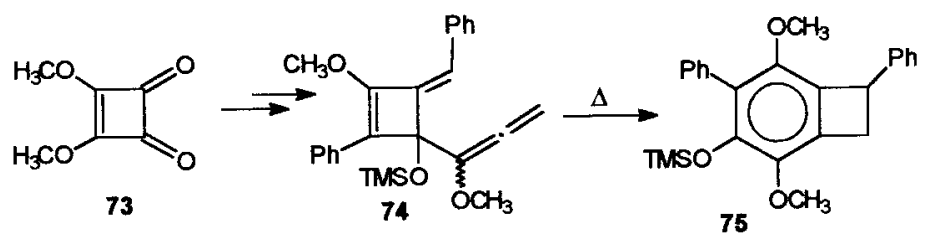

Scheme 42.

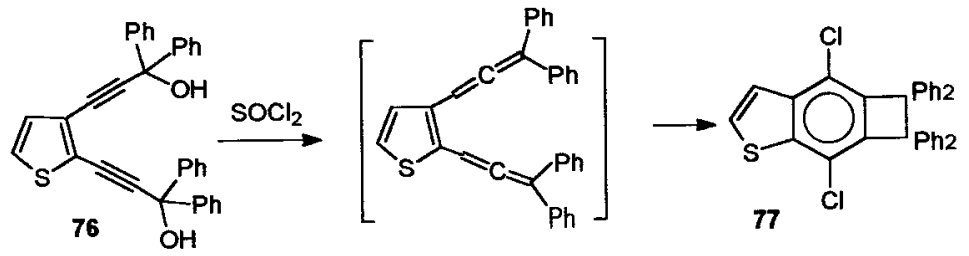

Scheme 43.

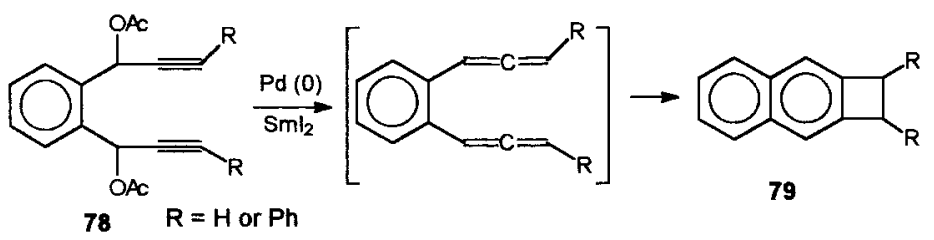

Scheme 44.

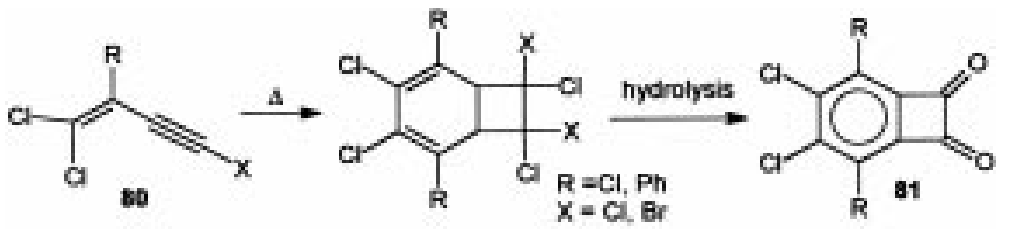


<smiles>[R]C1=C([R])C(Cl)C1=O</smiles>

82 (i) $(\mathrm{PhCN})_{2} \mathrm{PdCl}_{2}, \mathrm{TPP}$

(ii) $6 \mathrm{~N} \mathrm{HCl}, \mathrm{THF}, 60^{\circ} \mathrm{C}$<smiles>[R]c1cc2c(=O)c(=O)c2c(O)c1[R]</smiles>

84

Scheme 46.

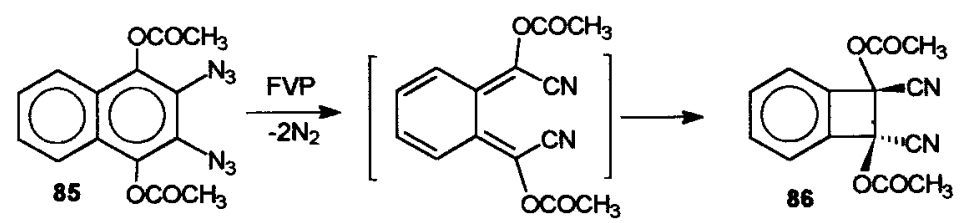

Scheme 47.

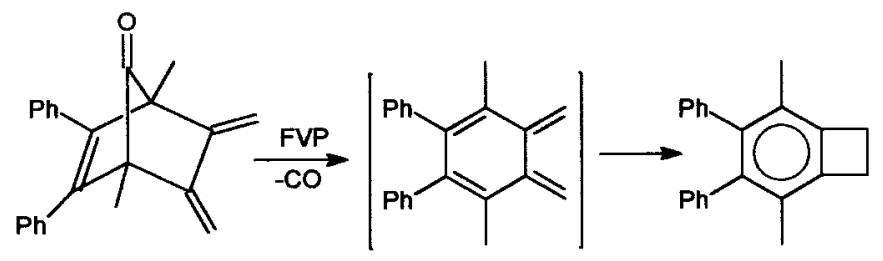

Scheme 48.

known routes. trans-1,2-Dicyanobenzocyclobutene $\mathbf{8 6}$ has been reported through FVP of 2,3-diazidonaphthalene $\mathbf{8 5}$ (Scheme 47). ${ }^{68}$ Another FVP-based method leading to a $\mathrm{BCB}$ derivative, which involves decarbonylation of a norbornenone derivative, has been reported by Warrener and co-workers (Scheme 48). ${ }^{69}$ An unusual uncaging of the caged trione $\mathbf{8 7}$ leading to the BCB derivative $\mathbf{8 8}$ has been observed during an attempted base-mediated Favorskii rearrangement (Scheme 49). ${ }^{70}$

The formation of a $\mathrm{BCB}$ derivative $\mathbf{8 9}$ involving radical cyclization as a key step is shown in Scheme $50 .^{71}$ Palladium-catalyzed reaction of 1,4-dibromobenzene with bicyclo[2.2.1]hept-2-ene led to the observation of products
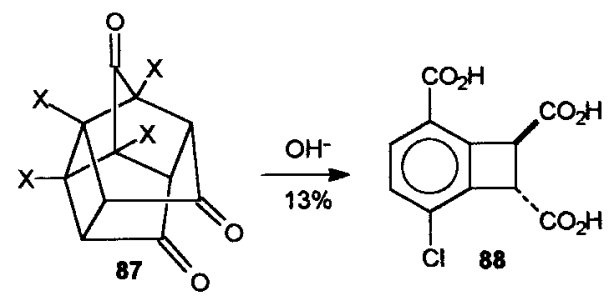

$\mathrm{X}=\mathrm{Cl}$, and any other halogen

Scheme 49.<smiles>O=C(C#CC#Cc1ccccc1)c1ccccc1Br</smiles><smiles>O=C1C(=Cc2ccccc2)c2ccccc21</smiles>

bearing a BCB moiety 90 derived from the insertion of norbornene into the aryl-palladium bond (Scheme 51). ${ }^{72}$

\section{Reactions of benzocyclobutenes}

The chemical reactivity of a BCBs can be manifested through either of the two rings. While the six-membered ring, as expected, exhibits reactions characteristic of an aromatic compound, the strained cyclobutane ring is prone to ring cleavage reactions. Alternatively, the ring opening of $\mathrm{BCB}$ to $o$-quinodimethane or $o$-xylylene intermediates provides the opportunity to explore its rich cycloaddition chemistry.

\subsection{Cyclobutane ring cleavage reactions}

The cyclobutane ring in BCB can be opened by proximal ring opening or by distal ring opening (Scheme 52). Thus, distal $\mathrm{C}-\mathrm{C}$ bond cleavage was observed during the Birch<smiles>Brc1ccc(Br)cc1</smiles>

Scheme 51.

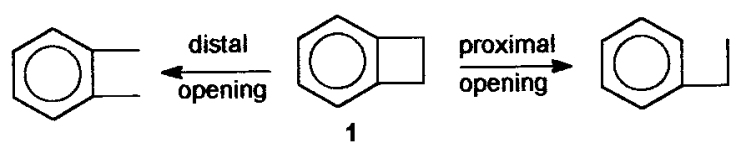

Scheme 52. 


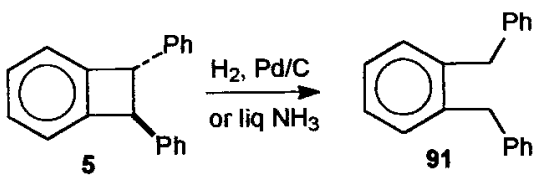

Scheme 53.

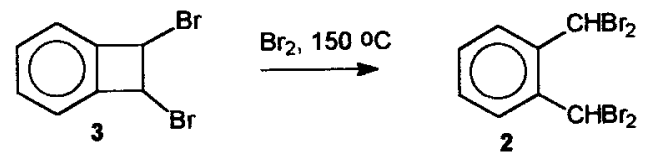

Scheme 54.

reduction of trans-1,2-diphenyl BCB 5 to give the $o$-dibenzyl derivative 91 as shown in Scheme 53. ${ }^{5}$ Similarly, in the addition of bromine to the BCB dibromide 3 , distal cyclobutane bond cleavage led to the $o$-xylene tetrabromide 2 (Scheme 54$).^{2}$ One of the early examples of distal C-C bond cleavage in BCBs was the base-mediated opening of benzocyclobutenols. Deprotonation of the benzocyclobutenol 92 leads to $o$-tolualdehyde anions which can be trapped by electrophiles such as aldehydes and nitriles to furnish the benzopyranols 93 and isoquinolines 94, respectively (Scheme 55). The benzopyranols 93 can be easily oxidized to 3 -substituted isocoumarins ${ }^{73}$ and this methodology has been applied to the synthesis of 3,4-dihydroiso- coumarin natural products. $o$-Tolualdehyde anions in the presence of nitriles cyclize to 3 -substituted isoquinoline derivatives 94 which are not readily accessible through standard Bischler-Napieralski isoquinoline synthesis. ${ }^{74}$ Recently, Olofson and co-workers have reported the preparation of various unsymmetrical anthracenes such as 95 by simultaneously generating the $o$-tolualdehyde anion and the benzyne intermediate from benzocyclobutenols and halogenated aromatic compounds, respectively, in the presence of lithium 2,2,6,6-tetramethylpiperidine (LiTMP) (Scheme 56). ${ }^{75}$ Exposure of the BCB derivative 96 bearing a tertiary hydroxy group to base furnished a distal ring-opened product 97 (Scheme 57). ${ }^{76}$ Interestingly, the regiochemistry of cyclobutane ring cleavage was reversed in the case of the tricarbonylchromium(0) complex 98 of 96 and the proximal bond cleavage product 99 was observed (Scheme 58).

Distal $\mathrm{C}-\mathrm{C}$ bond cleavage is also encountered in the benzocyclobutenone $\mathbf{1 0 0}$ which on exposure to sodium hydride gave the dimer $\mathbf{1 0 1}$ as the major product (Scheme 59). ${ }^{77} \mathrm{In}$ the presence of Li-TMP and an aromatic aldehyde, however, the benzocyclobutenone undergoes proximal $\mathrm{C}-\mathrm{C}$ bond cleavage and subsequent reaction with aldehyde gives the isochroman-3-one $\mathbf{1 0 2}$ in high yield. ${ }^{78}$

BCB 1, on the other hand, is known to undergo a proximal ring-opening reaction on treatment with sodium-potassium

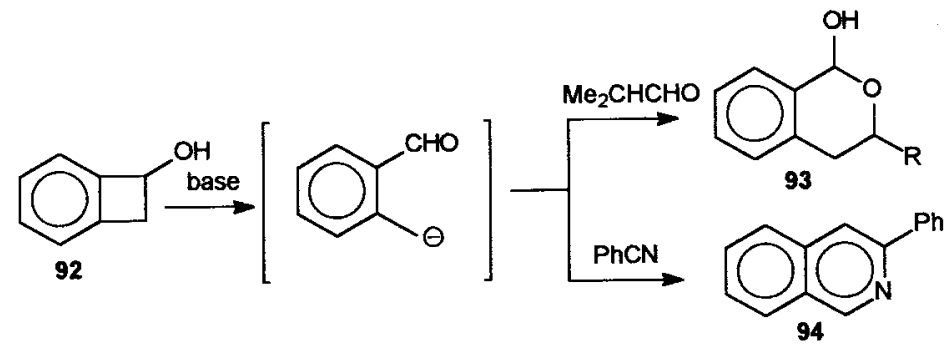

Scheme 55.

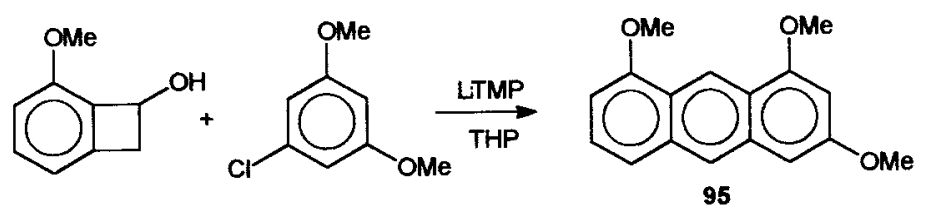

Scheme 56.

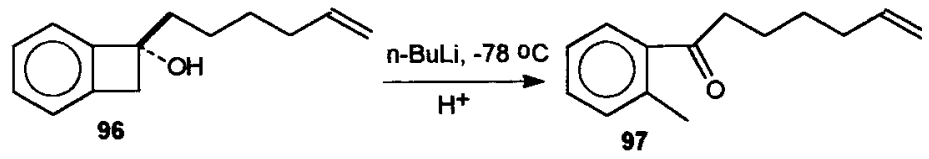

Scheme 57.

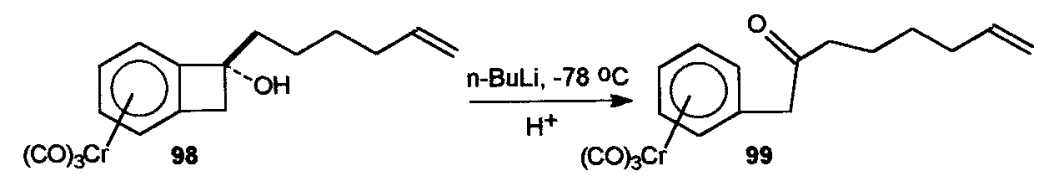




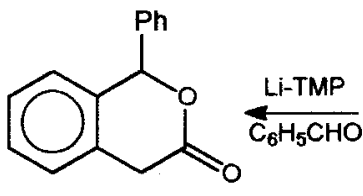

102

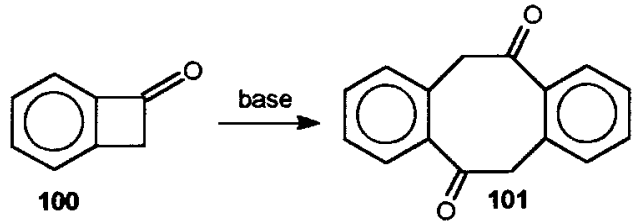

Scheme 59.

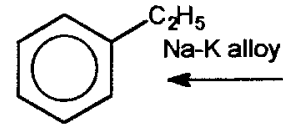<smiles>c1ccc2c(c1)CC2</smiles>

1<smiles>CCc1ccc2c(c1)CCc1c(CC)cccc1-2</smiles>

103

Scheme 60.

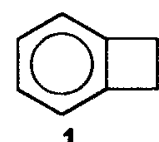

1<smiles>C[Hg]Br</smiles><smiles>BrCCc1ccccc1</smiles>

104 $\mathbf{1}$ at the proximal $\mathrm{C}-\mathrm{C}$ bond site to furnish phenylethyl bromide 104 (Scheme 61). ${ }^{81}$

\subsection{Electrophilic aromatic substitution reactions}

BCBs exhibit varying stability and susceptibility towards protic acids. For example, BCB remains unchanged on exposure to concentrated $\mathrm{HCl}$ but readily forms a viscous polymer with concentrated $\mathrm{H}_{2} \mathrm{SO}_{4}$ or liquid $\mathrm{HF}$. When electron withdrawing groups are present on the $\mathrm{BCB}$ ring, its stability towards strong protic acids is shown to be excellent. ${ }^{19 \mathrm{e}}$ This aspect is important because some BCB derivatives could be used in the synthesis of high-performance polymers requiring strong acids and high temperatures. In a super acid medium $\left(\mathrm{HF}-\mathrm{SbF}_{5} / \mathrm{SO}_{2} \mathrm{ClF}\right.$, $\left.-90^{\circ} \mathrm{C}\right), \mathrm{BCB}$ rearranges to a stable phenonium ion $\mathbf{1 0 5}$ (Scheme 62). ${ }^{82}$

Classical electrophilic substitution reactions have been exploited to prepare aryl-substituted BCBs as shown in Scheme 63. For example, direct bromination of BCB 1

Scheme 62.<smiles>Brc1ccc2c(c1)CC2</smiles><smiles>Cc1ccc2c(c1)CC2</smiles><smiles>C[14CH2][14CH2]c1ccc2c(c1Br)CC2</smiles><smiles>CC1(C#N)Cc2ccc(O)cc2C1</smiles><smiles>C#CC1Cc2ccc([N+](=O)[O-])cc2C1</smiles>

Scheme 63. (i) $\mathrm{Br}_{2}, \mathrm{I}_{2}$ (cat), $\mathrm{AcOH}$; (ii) $n$-BuLi/TMEDA, TMSCl, $\mathrm{Br}_{2}$; (iii) $\mathrm{K}-10$ clay, $\mathrm{Ac}_{2} \mathrm{O}, \mathrm{HNO}_{3}$; (iv) $\mathrm{TiCl}_{4}, \mathrm{Cl}_{2} \mathrm{CHCOCH}_{3}$; (v) permonophosphoric acid.<smiles>P=Cc1ccc2c(c1)CC2</smiles><smiles>C=Cc1ccc2c(c1)CC2</smiles>

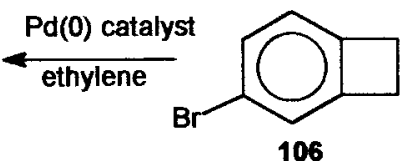




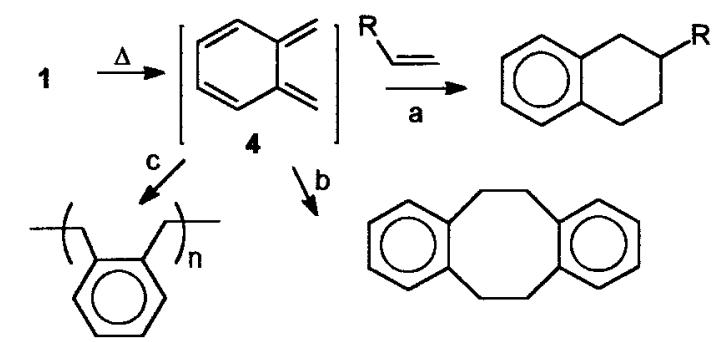

Scheme 65.

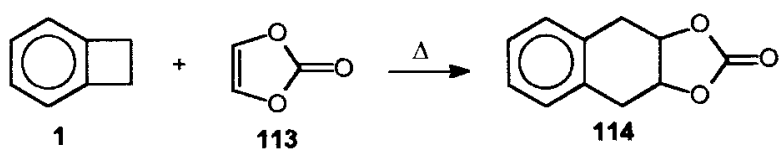

Scheme 66.

gives 4-bromobenzocyclobutene 106, whilst 3-bromobenzocyclobutene $\mathbf{1 0 7}$ could be prepared in an indirect manner using metalation as the key step. ${ }^{83}$ Although the metalation reaction does not give very high yields, this procedure is useful for the preparation of various 3-substituted BCBs. Formylation of BCB gave $\mathbf{1 0 8}$ which upon further $\mathrm{BV}$ oxidation was transformed to the corresponding phenol 109. ${ }^{84}$ Nitration of BCB 1 using acetyl nitrate (generated in situ by a continuous process) in the presence of a montmorillonite K-10 clay catalyst gave 4-nitro BCB 110 in $60 \%$ yield which is a two-fold increase over known methods. ${ }^{85}$ Substituted BCBs obtained by electrophilic substitution are precursors of industrially important products. For example, the vinyl BCB derivative 111, which is an important building block for high performance $T_{\mathrm{g}}$-thermoset polymers, is accessed from either 4-bromo BCB 106 via $\operatorname{Pd}(0)$ mediated Heck coupling or through Wittig olefination of the ylide 112 (Scheme 64). ${ }^{86}$

\subsection{Thermally induced reactions}

$\mathrm{BCB}$ undergoes three types of reactions under thermal activation. It is well established that BCBs readily isomerize to $o$-xylylene 4, which can be trapped with various dienophiles in inter- and intramolecular fashion to generate various polycyclic systems (path a, Scheme 65). $o$-Xylylene intermediates in the absence of dienophiles dimerize or polymerize. The dimerization process has been employed

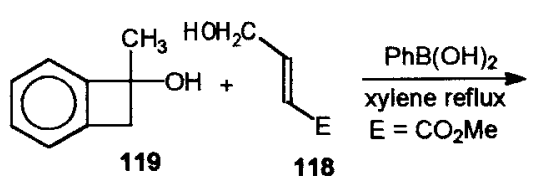<smiles>CC1Cc2ccccc2C2(C)OB(c3ccccc3)OCC12</smiles>

Scheme 69.

for the preparation of cyclophanes from suitably substituted benzocyclobutene precursors (path b). Alternatively, polymerization (path c) constitutes an important route for the synthesis of high performance polymers for applications in the electronics and aerospace industries. The fate of $o$-xylylene in the absence of other co-reactive species appears to depend to a large extent upon the conditions under which it is generated.

A range of dienophilic partners engage $\mathrm{BCBs}$ via their $o$-xylylene intermediates in [4+2] cycloadditions. A few representative examples will be discussed here. Addition of $\mathrm{BCB}$ to vinylene carbonate $\mathbf{1 1 3}$ and anthracene $\mathbf{1 1 5}$ leads to Diels-Alder adducts 114 (Scheme 66) and $\mathbf{1 1 6}$ (Scheme 67), respectively. ${ }^{87-88}$ The cycloaddition of $o$-xylylene to an arene 1,4-oxide $\mathbf{1 1 7}$ was used to construct a linear arene array (Scheme 68). ${ }^{89}$ Phenylboronic acid has been used as a template in the Diels-Alder reaction between methyl 4-hydroxy-2-butenoate 118 and the $\alpha$-hydroxy-oxylylene intermediate generated from the benzocyclobutenol 119 by thermolysis (Scheme 69).$^{90}$ Charlton et al have described a highly diastereoselective Diels-Alder addition between the $\alpha$-hydroxy- $o$-xylylene derived from 120 and a fumaric acid diester bearing a chiral auxiliary (Scheme 70). ${ }^{91}$ Keay and co-workers have reported that 1-methoxybenzocyclobutenes such as $\mathbf{1 2 1}$ are good substrates for the preparation of highly functionalized naphthalene derivatives $\mathbf{1 2 2}$ via [4+2] cycloaddition (Scheme 71). ${ }^{92}$ Recently, a polymer-supported BCB derivative 123 bearing a traceless linker has been shown to undergo Diels-Alder reactions with homo- and heterodieneophiles. The adducts formed may be cleaved from the solid support in both reductive and $\mathrm{C}-\mathrm{C}$ bond forming modes (Scheme 72) ${ }^{93}$ Intramolecular [4+2] cycloadditions of BCBs via $o$-xylylene intermediates proceed in a very facile manner and, later in this review, several applications of this protocol to natural product synthesis will be described.
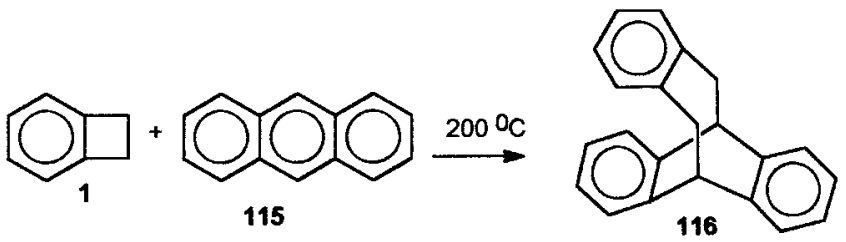

Scheme 67.

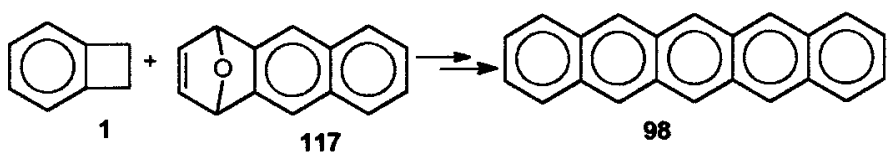




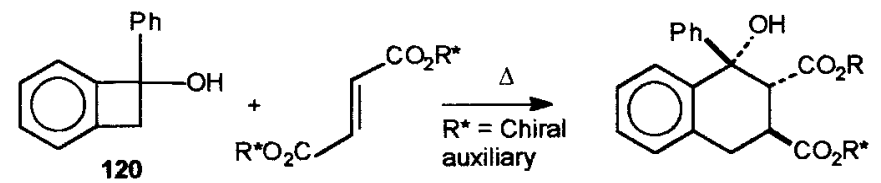

Scheme 70.<smiles>CCOC1Cc2c(OC)ccc(OC)c21</smiles>

Scheme 71 .

BCB-derived $o$-xylylene intermediates bearing an additional conjugating $2 \pi$ component on thermal activation exhibit a propensity towards $6 \pi$ electrocyclization to generate six-membered rings. Fukumoto and co-workers have reported $^{94}$ the construction of the naphthalenic portion $\mathbf{1 2 6}$ of the antitumor antibiotic neocarzinostatin employing an

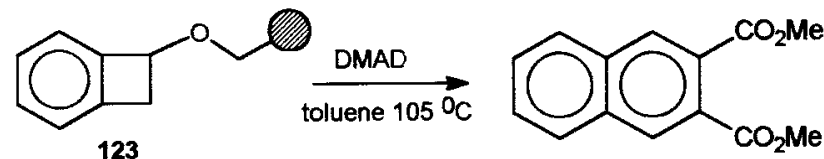

electrocylic reaction of the intermediate $o$-xylylene $\mathbf{1 2 5}$ derived from the BCB derivative $\mathbf{1 2 4}$ as the key step (Scheme 73). A similar strategy has been employed for the synthesis of naproxen (Scheme 74). ${ }^{95} \alpha$-Tetralones such as 129 are prepared from the benzocyclobutenol 127 via a sequential thermal electrocyclic reaction of the intermediate 128 (Scheme 75). ${ }^{96}$ Under thermal activation, the benzocyclobutenyl ketone oximes 130 gave 3,4-disubstituted isoquinolines $\mathbf{1 3 2}$ via $o$-xylylene intermediates 131 (Scheme 76). ${ }^{97}$

\subsection{Photochemical reactions}

Irradiation of the parent BCB $\mathbf{1}$ in pentane solution at $254 \mathrm{~nm}$ yields two dihydropentalenes 133 and 134 (Scheme 77). ${ }^{98}$ In the irradiation of substituted BCBs, however, electrocyclic ring opening to $o$-xylylene is the major pathway. Thus, the photo-induced cycloaddition of cis-1,2diphenyl BCB 135 to tetracyanoethylene to furnish the [4+2] cycloaddition product $\mathbf{1 3 6}$ has been reported (Scheme 78). ${ }^{99}$ cis-1,2-Diphenyl BCB 135 on irradiation in the presence of 9,10-dicyanoanthracene gave significant

Scheme 72

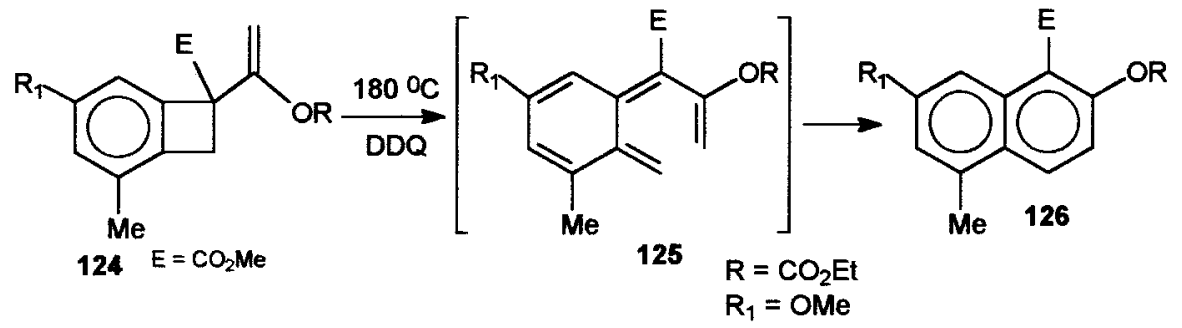

Scheme 73.

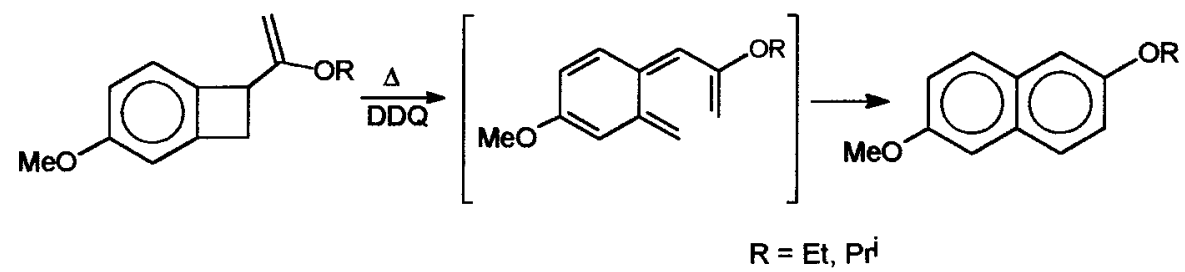

Scheme 74.<smiles>COc1ccc(OC)c2c1CC2(C=CC(=O)O)OC</smiles><smiles>C=c1c(OC)ccc(OC)c1=C(C)C=CC(C)O</smiles>

128<smiles>COc1ccc(OC)c2c1CC([C@H](C)O)CC2=O</smiles>

129 
<smiles>[R]C(=NO)C1([R])Cc2ccc(OC)cc21</smiles>

130

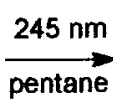

1

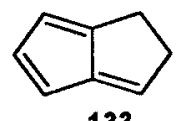

133

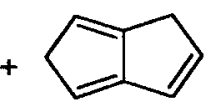

134
Scheme 77.

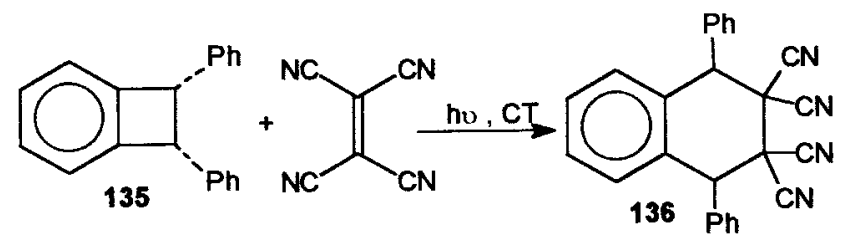

Scheme 78.

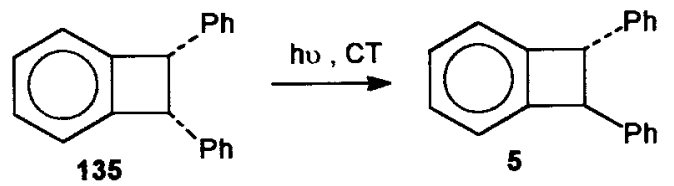

amounts of trans-diphenyl BCB 5 via the corresponding $o$-xylylene intermediate (Scheme 79). Kobayashi et al have reported a general method for the synthesis of the phthalides 138 from BCB derivatives. This methodology involves regioselective single or double $\beta$-scission of the alkoxy radicals generated by photolysis of the hypoiodite 137 of 1-ethyl-benzocyclobuten-1-ol 136 (Scheme 80). ${ }^{100-101}$ Lastly, irradiation of the benzocylobutenone $\mathbf{1 0 0}$ in methanol gave the methyl benzoate as the major product, presumably involving the ketene intermediate 139 (Scheme $81)^{26,102}$

\subsection{Oxidation and reduction reactions}

BCB 1 shows a unique reactivity towards the soil bacterium Pseudomonas putida when compared to other benzocycloalkenes. Biotransformation of BCB gave monooxygenation, dioxygenation and trioxygenation products involving a complex metabolic profile (Scheme 82). ${ }^{103}$ Oxidation of BCB by intact cells of Pseudomonas fluorescens 127-68 XVII, containing naphthalene dioxygenase, yielded exclusively the benzylic oxidation products, benzocyclobutene-1-ol 92 and benzocyclobutene-1-one 100. ${ }^{104}$ No evidence for the incorporation of oxygen into

Scheme 79.

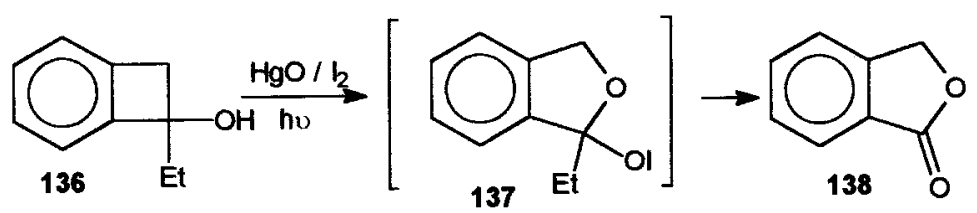

Scheme 80 .

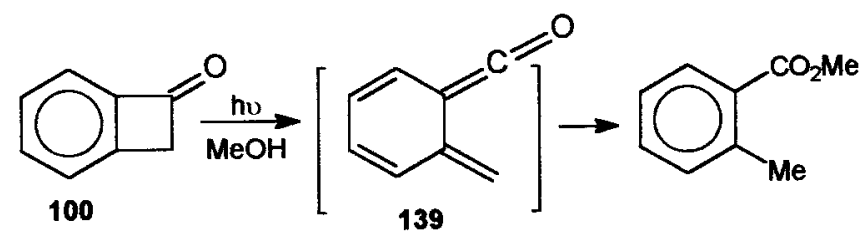

Scheme 81.
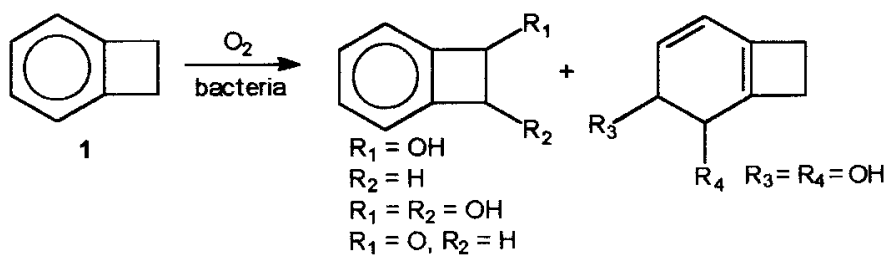

$R_{1}=O, R_{2}=H$ 

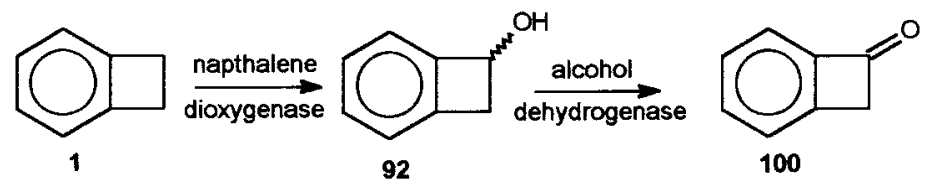

Scheme 83.<smiles>[R]Oc1cccc2c1OC(=O)C2</smiles>

Scheme 84.

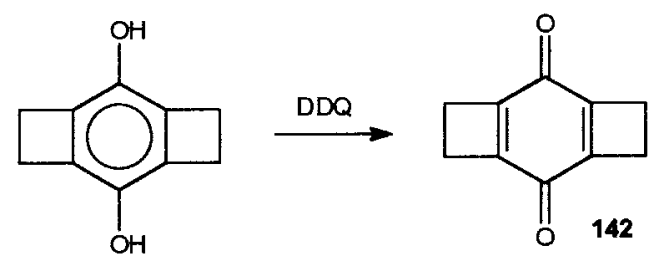

Scheme 85.

the aromatic ring was found (Scheme 83). Bayer-Villiger oxidation of benzocyclobutenones such as $\mathbf{1 4 0}$ proceeds with rigorous regioselectivity to give the phthalides 141 in high yield (Scheme 84). ${ }^{105}$ DDQ was found to be a useful oxidizing reagent to generate the dicyclobuta- $p$-benzoquinone derivative 142 (Scheme 85$).^{40}$

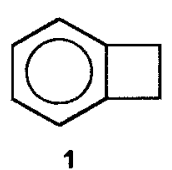

Scheme 86.

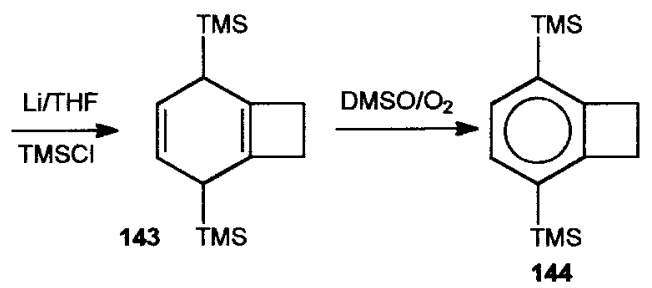

The arene ring of $\mathrm{BCBs}$ undergoes Birch reduction along the expected lines. Reductive silylation of BCB 1 under Birch reduction conditions or on electrochemical reduction gives the unsaturated derivative 143 which on rearomatization in air gave the 3,6-bis-(trimethylsilyl) BCB derivative 144 (Scheme 86). ${ }^{23}$ Birch reduction of 145 was a key step in the synthesis of grandisol (Scheme 87). The aromatic ring in the $\mathrm{BCB}$ derivative $\mathbf{1 4 5}$ was reduced to the bicyclic enone 146 and further elaborated to grandisol via ring cleavage reactions. ${ }^{106}$

\subsection{Ring adjustment reactions}

Appropriately substituted BCBs can be restructured through ring expansion and ring contraction protocols. Thus, the benzocyclobutenol 147 can be either converted to the indanone 148 on treatment with protic acids or to the benzocyclooctenone 149 by base (Scheme 88). ${ }^{107}$ Solvolysis of benzocyclobuten-1-ylcarbinyl toluenesulfonate 150 results in ring expansion to indene $\mathbf{1 5 2}$ via the intermediate $\mathbf{1 5 1}$ (Scheme 89). ${ }^{108}$ Similarly, the benzocyclobutenyl alcohol 153 rearranges to the indane derivative 154 when reacted with $\mathrm{SO}_{2} \mathrm{Cl}$ (Scheme 90). ${ }^{109}$ 8-Hydroxy-4a,5,8,8a-tetrahydrobiphenylene-5-carboxylic acid $\mathbf{1 5 5}$ undergoes an acid-catalyzed rearrangement to give the bridged benzocycloheptane derivative 156. Interestingly, no products derived from the thermodynamically favored benzylic cation could be found (Scheme 91). ${ }^{110}$
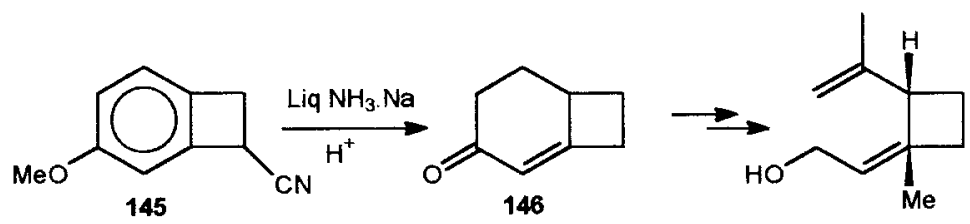

grandisol

Scheme 87.

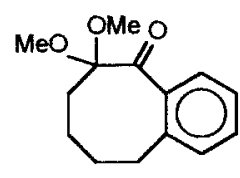

149<smiles>COC1(OC)CCCC2c3ccccc3C21O</smiles>

147<smiles>COC12CCCC1c1ccccc1C2=O</smiles>

148 

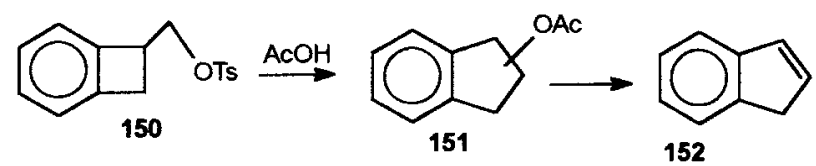

Scheme 89.

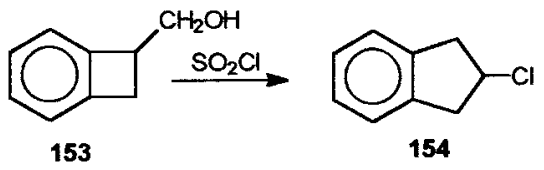

Scheme 90.

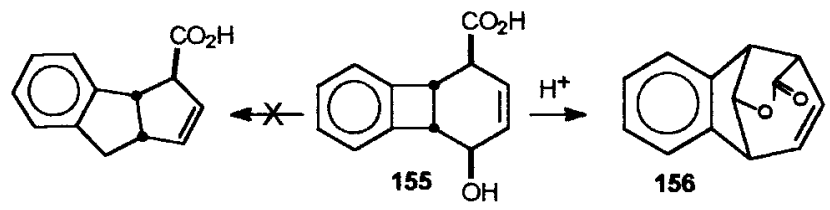

Scheme 91.

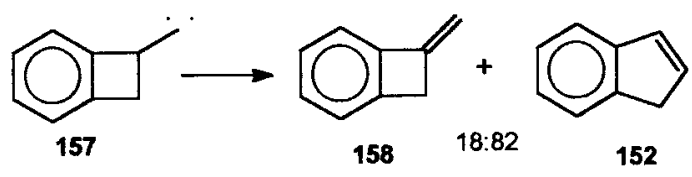

Scheme 92.

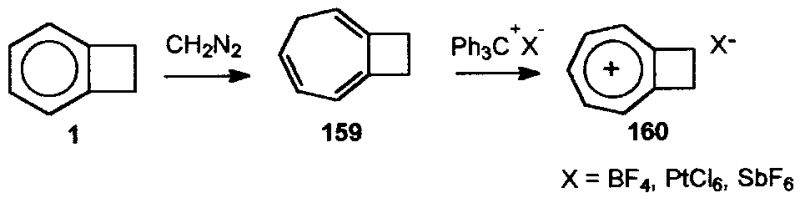

Scheme 93.

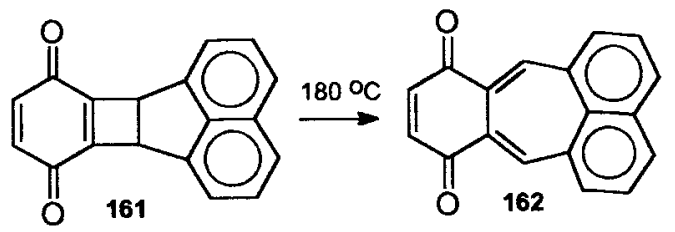

Scheme 94.
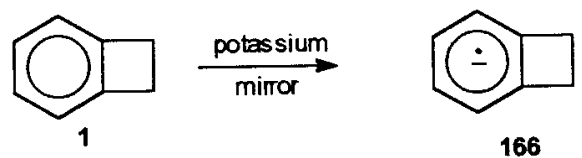

Scheme 96.

Benzocyclobuten-1-ylcarbene 157 generated under photolytic conditions gave 1-methylenebenzocyclobutene $\mathbf{1 5 8}$ and indene $\mathbf{1 5 2}$ in a ratio of 18:82 (Scheme 92). ${ }^{111}$ Interestingly, the reactive methylene from diazomethane inserts into the aromatic ring of $\mathrm{BCB}$ to furnish a mixture of cyclobutane-fused cycloheptatrienes (e.g. 159). Treatment of this mixture with a trityl salt affords the cyclobutane-fused tropylium salt $\mathbf{1 6 0}$ in an essentially pure form (Scheme 93). ${ }^{112} \mathrm{~A}$ new pleiadenequinone $\mathbf{1 6 2}$ with considerable electron affinity was prepared via ring expansion of the BCB-based quinone 161 (Scheme 94). ${ }^{113}$

BCB carboxylic acid derivatives 163 undergo an alkoxidemediated oxidative ring expansion to the hydroxyindanones 164 as shown in Scheme 95. These indanones can be further converted to dihydroisocoumarine derivatives such as $\mathbf{1 6 5}{ }^{114}$

\subsection{Reactive intermediates involving $\mathrm{BCBs}$}

Reduction of $\mathrm{BCB}$ with a potassium mirror at $-78^{\circ} \mathrm{C}$ generates the stable $\mathrm{BCB}$ radical anion 166, having a characteristic 69-line ESR spectrum (Scheme 96). ${ }^{115}$ When BCB is contacted with $\mathrm{K}$ or $\mathrm{Na} / \mathrm{K}$ in $\mathrm{THF}$ at $-80^{\circ} \mathrm{C}$, however, the only radical which is observed, and which is formed virtually immediately, is the anion radical of $o$-xylylene 167 (Scheme 97) ${ }^{116}$ Cyclobuta[1,2- $\left.d\right]$ benzyne 169 has been generated from 4,5-bromoiodobenzocyclobutene $\mathbf{1 6 8}$ and butyllithium (Scheme 98). The transient reactive species can be trapped with furan as the Diels-Alder adduct 170. In the absence of trapping agents, dimerization of the intermediate benzyne is observed. ${ }^{11}$

\subsection{Reactions via benzocyclobutadiene}

Transient benzocyclobutadiene intermediates are readily generated from BCBs and exhibit novel reaction products. For example, the trans-dibromide $\mathbf{3}$ is rapidly debrominated under a variety of reaction conditions to give the intermediate benzocyclobutadiene 171 which undergoes a range of dimerization and trimerization reactions (Schemes 99-102). ${ }^{118}$

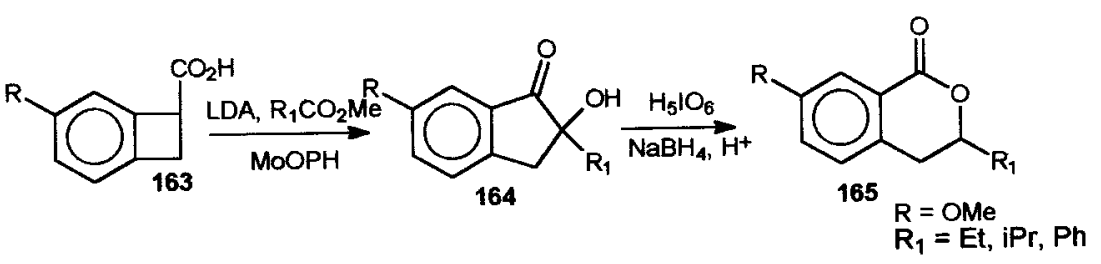




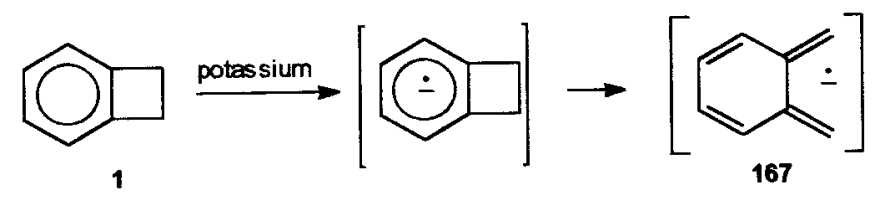

Scheme 97.

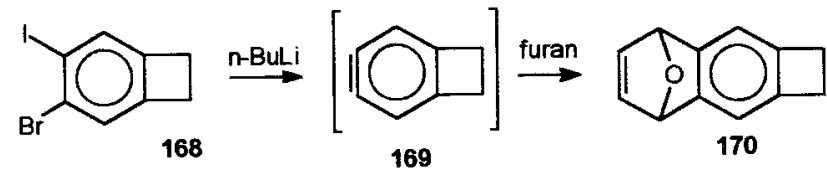

Scheme 98.

\subsection{Miscellaneous reactions of $\mathrm{BCBs}$}

Many interesting but isolated reactions of $\mathrm{BCBs}$ reported in the recent literature are described in this section. An unex- pected rearrangement of the spiro[benzocyclobutene- $1,3^{\prime}$ piperidine] $\mathbf{1 7 2}$ in the presence of aluminium trichloride has been reported (Scheme 103). ${ }^{119}$ Application of the Schmidt reaction to 1,2-dihydrobenzocyclobutenol derivatives 173 provides a new route to indole derivatives as shown in Scheme 104. ${ }^{120}$ Reductive coupling of 1-chloro BCB 174 with a chromium(0) complex led to the corresponding dimer 175 (Scheme 105). ${ }^{121}$ Nucleophilic substitution in perchlorobenzocyclobutenes such as $\mathbf{1 7 6}$ in methanolic sodium hydroxide leads to the methoxy-substituted derivative 177 (Scheme 106). ${ }^{122}$

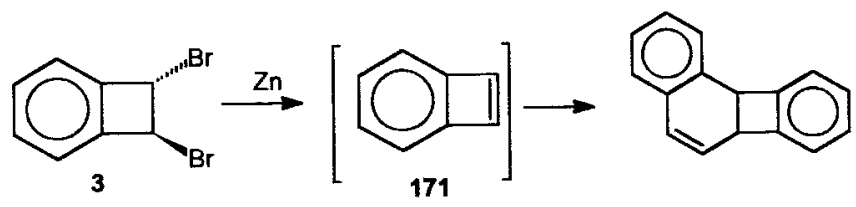

Scheme 99.<smiles>BrC1c2ccccc2[C@@H]1Br</smiles>

Scheme 100.

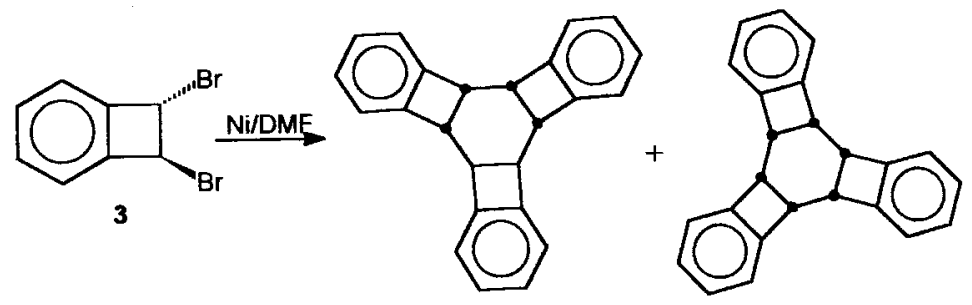

Scheme 101.<smiles>BrCc1c(CC2CC2CBr)c2ccccc2c2ccccc12</smiles>

Scheme 102.

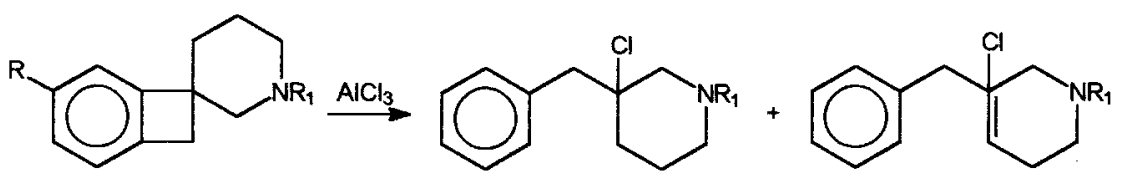

$172 \mathrm{R}=\mathrm{OMe}, \mathrm{HR}_{1}=\mathrm{CH}_{2} \mathrm{Ph}, \mathrm{H}$ 


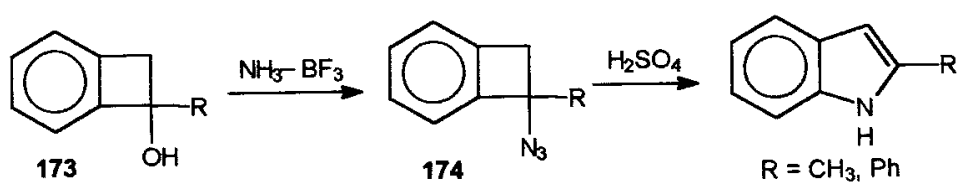

Scheme 104.

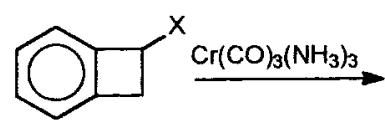

$72 \mathrm{X}=\mathrm{Cl}$

Scheme 105.

Tricarbonylchromium(0) BCB 178 can be readily deprotonated with $n$-BuLi/-TMEDA base and quenching of the anion with chlorotrimethylsilane leads to the formation of the 3- and 4-trimethylsilyl derivatives $\mathbf{1 7 9}$ and $\mathbf{1 8 0}$ (Scheme 107). ${ }^{123}$

\section{Reactions of benzocyclobutenedione (BCBD)}

Benzocyclobutenediones (BCBDs) are important deriva- tives of BCBs and exhibit interesting chemical reactivity. The orthoquinonoid vinylketenes generated thermally or photochemically from a BCBD such as $\mathbf{1 8 1}$ undergo cycloaddition with a bicyclic benzoquinone derivative 182 to yield tetracyclic 10-deoxydaunomycinone derivative $\mathbf{1 8 3}$ (Scheme 108). ${ }^{124}$ Staab and Ipaktschi have reported that the photolysis of benzocyclobutene-1,2-dione $\mathbf{5 2}$ in the absence of trapping reagents led to the formation of a number of dimers such as $\mathbf{1 8 5}$ and $\mathbf{1 8 6}$ and their formation is indicative of the intermediacy of the bis-ketene $\mathbf{1 8 4}$ (Scheme 109). ${ }^{125}$ Reactions of arenetricarbonylchromium( 0 ) complexes of the BCBD show an interesting reactivity pattern. The BCBD complex 187, when reacted with excess vinyllithium, furnished the benzoannulated cyclooctane-1,4dione $\mathbf{1 8 9}$ as a result of a double anionic oxy-Cope rearrangement in 188 (Scheme 110). ${ }^{126}$ Iron metallocycles, such<smiles>Clc1c(Cl)c(Cl)c2c(c1Cl)C(Cl)(Cl)C2(Cl)Cl</smiles><smiles>COc1c(Cl)c(Cl)c2c(c1Cl)C(Cl)(Cl)C2(Cl)Cl</smiles><smiles>COc1c(Cl)c(Cl)c2c(c1Cl)C(Cl)(Cl)C2(C)OC</smiles>

Scheme 106.
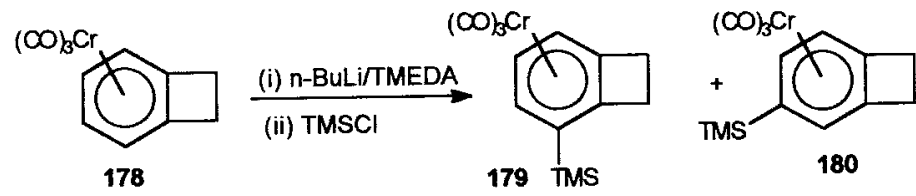

Scheme 107.<smiles>COc1ccc(OC)c2c1C(=O)[CH+]2CCCCCCCCCCC(C)=O</smiles>

Scheme 108.<smiles>CC(C)[C@@H](C)C(=O)c1ccccc1C=O</smiles> 


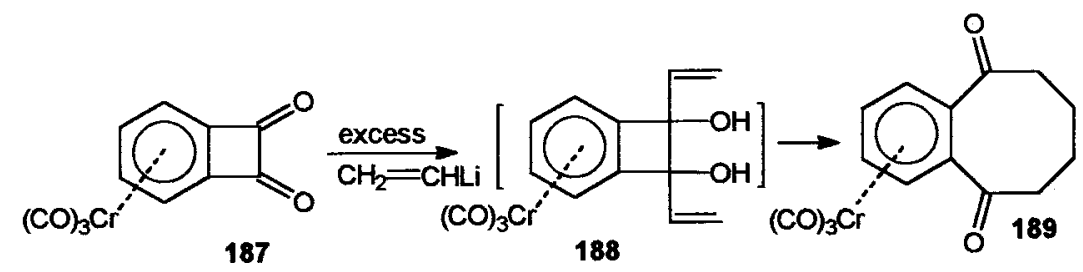

Scheme 110.

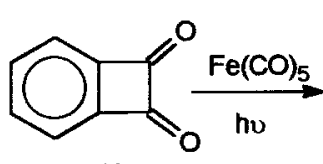

52

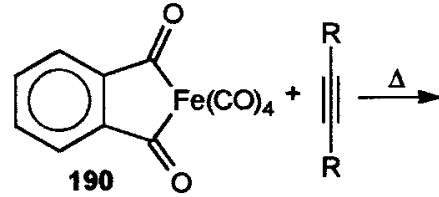

190<smiles>[R]C1=C([R])C(=O)c2ccccc2C1=O</smiles>

$\mathrm{R}=\mathrm{CO}_{2} \mathrm{Me}$

Scheme 111.

as 190, derived from $\mathrm{BCBD}$ react with a wide variety of alkynes to give naphthoquinones 191 in good yields (Scheme 111). ${ }^{127}$

\section{Applications of $\mathrm{BCBs}$ in synthesis}

As mentioned earlier, the major applications of BCBs in syntheses emanate through their ready conversion to $o$-xylylene intermediates that exhibit a high propensity towards inter- and intramolecular cycloadditions. The use of pre-formed $\mathrm{BCB}$ derivatives in complex synthesis was introduced by Oppolzer in 1971 with his seminal synthesis of the isoquinoline alkaloid chelidonine. ${ }^{128}$ Following on from this work, several other groups have used BCB- derivatives extensively as starting materials to generate various polycyclic frameworks of biological and theoretical importance. Representative targets of topical interest that have been pursued via the BCB route are shown in Fig. 3. In order to limit the size of this article, a small selection of examples to demonstrate the synthetic utility of BCBs are now presented.

\subsection{Alkaloid synthesis}

The inter- and intramolecular Diels-Alder reaction has been widely used as a key step in the stereocontrolled synthesis of various heterocyclic compounds via $\mathrm{BCB}$ intermediates. The three possible strategies through which heteroatom(s)

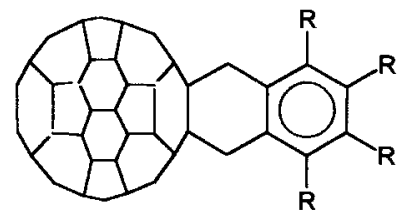

fullerene derivatives<smiles>[R]c1c([R])c([R])c2c(c1[R])C([R])([R])C2([R])[R]</smiles>

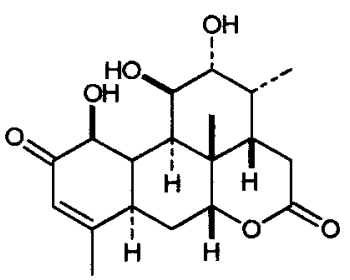

quassinoid

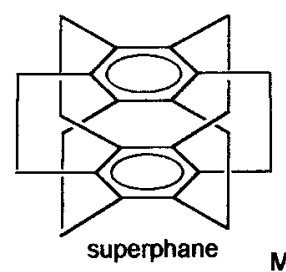

estrone<smiles>COc1ccc2c(c1)CCC1C2CCC2(C)C(=O)CCC12</smiles><smiles>COc1cccc2c(O)c3c(c(O)c12)C(=O)C1C(O)CC(O)(C(C)=O)CC1C3=O</smiles>

daunomycinone<smiles>NC(Cc1ccc2c(c1)CC2)C(=O)O</smiles>

BCB-base amino acid<smiles>CN1Cc2c(ccc3c2OCO3)[C@H]2[C@@H](O)Cc3cc4c(cc3[C@@H]21)OCO4</smiles>

Figure 3. Application of BCB-based strategies for various molecular frameworks. 


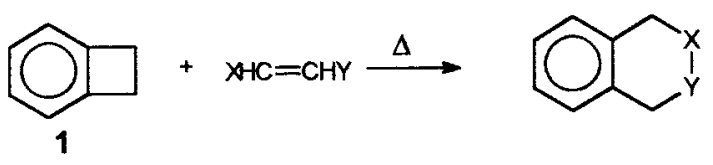

Scheme 112.<smiles>[Y]CCCC1c2ccccc2C1[X]</smiles>

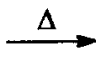

Scheme 113.
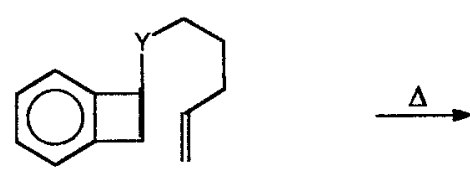

Scheme 114.

can be introduced into the target structures via the $\mathrm{BCB}$ route are shown in Schemes 112-114.

As mentioned above, the first application of $o$-xylylenes in the natural product area was the synthesis of chelidonine 194, the main alkaloid of Chelidonium majus, from the BCB derivative 192. Thermal activation of $\mathbf{1 9 2}$ gave 193 in $73 \%$ yield via the $o$-xylylene intermediate which was further elaborated to dl-chelidonine 194 (Scheme 115). ${ }^{128}$
In studies aimed at the synthesis of antitumor carbazole alkaloids such as olivacine and ellipticine, indolylmagnesium bromide 195 was reacted with 1-cyano-4,5dimethoxybenzocyclobutene 196 to produce a mixture of compounds which could be aromatized to the benzocarbazole derivatives 197 under dehydrogenating conditions (Scheme 116). ${ }^{129}$ A regioselective intermolecular cycloaddition between the $o$-xylylene intermediate derived from the 1-cyanobenzocyclobutene $\mathbf{1 9 8}$ and 3,4-dihydro- $\beta$ carboline 199, and reductive decyanation afforded the pentacyclic hexadehydroyohimbane 200 (Scheme 117). ${ }^{130}$ A novel and general route to the morphinane alkaloid skeleton 201 was reported via an intramolecular [4+2] cycloaddition reaction of a $\mathrm{BCB}$ derivative (Scheme 118). ${ }^{131}$

The tetracyclic framework 203, present in the complex aconite-garaya diterpene alkaloids, has been constructed via an electrocyclic reaction of the $(Z)$-o-quinodimethane $\mathrm{BCB}$ derivative derived from $\mathbf{2 0 2}$ under thermal conditions (Scheme 119). ${ }^{132}$

A one-pot procedure has been developed for the synthesis of 4,4-disubstituted isochroman-3-ones 206 using the tandem electrocyclic-[3,3] sigmatropic reaction of the (Z)-o-xylylene 205 starting from the BCB derivative 204 (Scheme 120). ${ }^{133}$ The isochroman derivative 206 is a useful intermediate in the synthesis of various indole alkaloids. The tetrahydroprotoberberine alkaloid, ( \pm )-tetrahydropalmatine 209, was synthesized through cycloaddition in the 1-benzocyclobutenyl-3,4-dihydroisoquinoline 207, followed by reduction of the enamine $\mathbf{2 0 8}$ with sodium borohydride

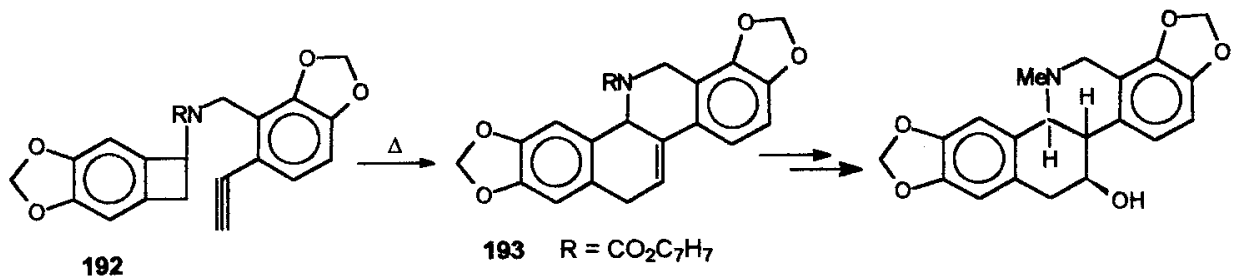

Scheme 115.<smiles>COc1cc2c(cc1OC)C(Cl)C2</smiles>

196<smiles>[Mg][Mg]</smiles>

195<smiles>C#CCCCC</smiles><smiles>[R]c1c2ccccc2c([R])c2c1[nH]c1ccccc12</smiles>

$$
R=C N, R^{\prime}=H ; R=H, R^{\prime}=C N
$$

Scheme 116.<smiles>COc1ccc2c(c1)C(C#N)C2</smiles>

198<smiles>C1=NCCc2c1[nH]c1ccccc21</smiles><smiles>Nc1ccccc1</smiles><smiles>COc1ccc2c(c1)CC1c3[nH]c4ccccc4c3CCN1C2</smiles> 


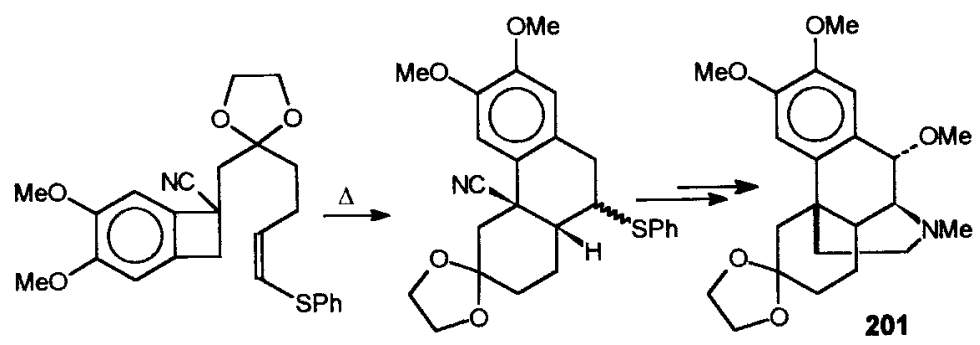

Scheme 118.

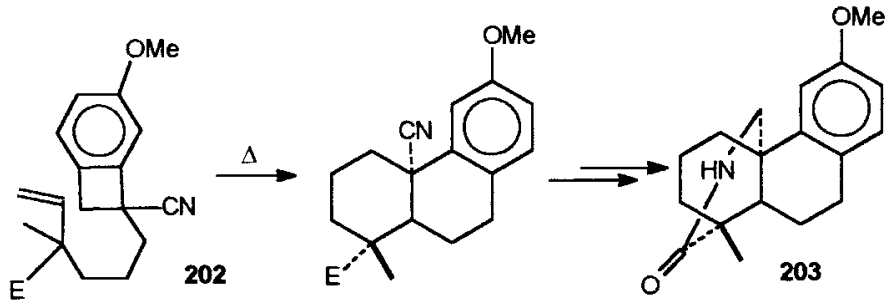

Scheme 119.

(Scheme 121). ${ }^{134}$ The ochotensine type spirobenzylisoquinoline 211 was prepared via an electrocyclic reaction of the corresponding BCB derivative $\mathbf{2 1 0}$ (Scheme 122). ${ }^{135}$

\subsection{Steroid synthesis}

The strategy for the synthesis of the steroid framework via
$\mathrm{BCB}$ derivatives comprises the two stages shown in Scheme 123. The first stage involves the construction of an appropriately substituted BCB derivative $\mathbf{2 1 2}$ containing a dienophilic moiety and in the second stage the $(E)-o$-xylylene intermediate 213 derived from BCB 212 participates in an intramolecular cycloaddition reaction in a regio- and stereoselective manner to form the tetracyclic derivative $\mathbf{2 1 4}{ }^{136}$

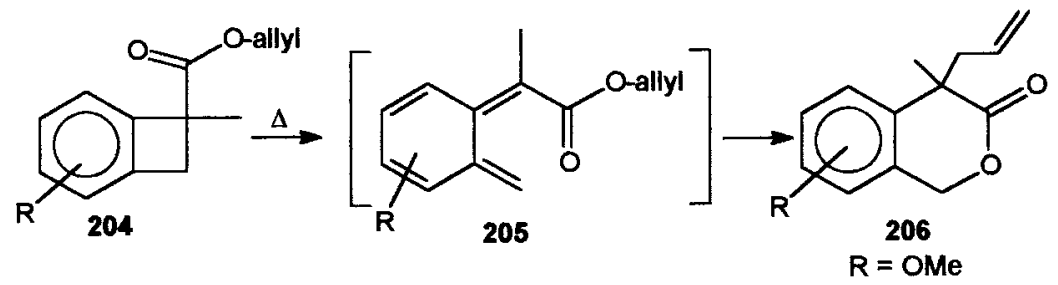

Scheme 120.

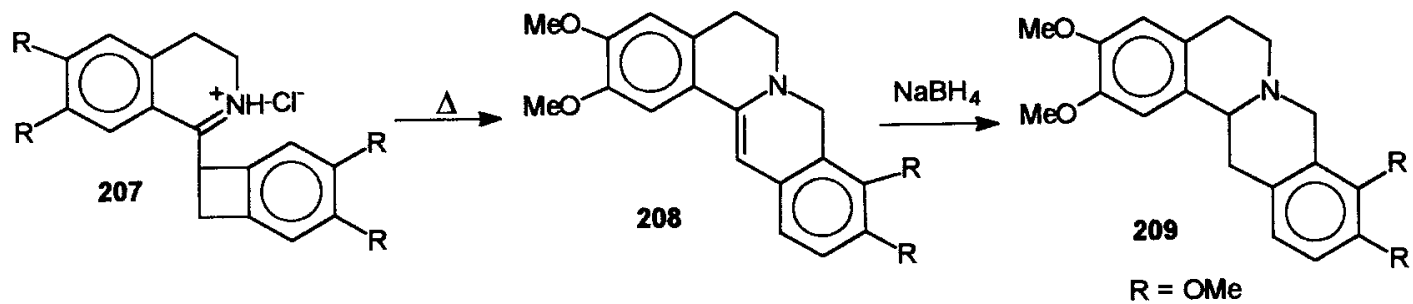

Scheme 121.<smiles>COc1ccc(CCNC(=O)C2Cc3cc(OC)c(OC)cc32)cc1OC</smiles>

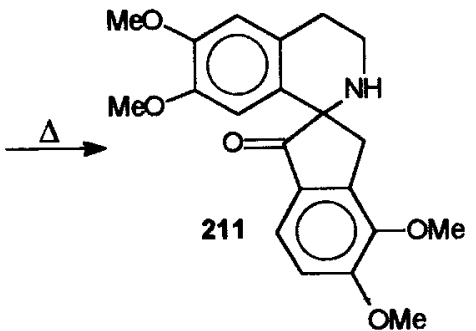




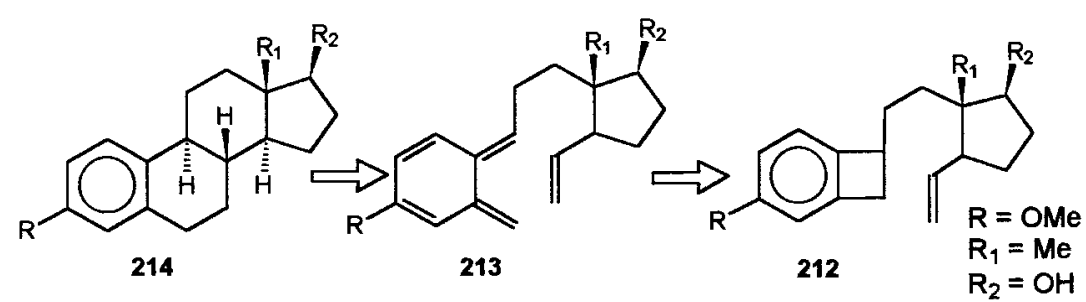

Scheme 123.

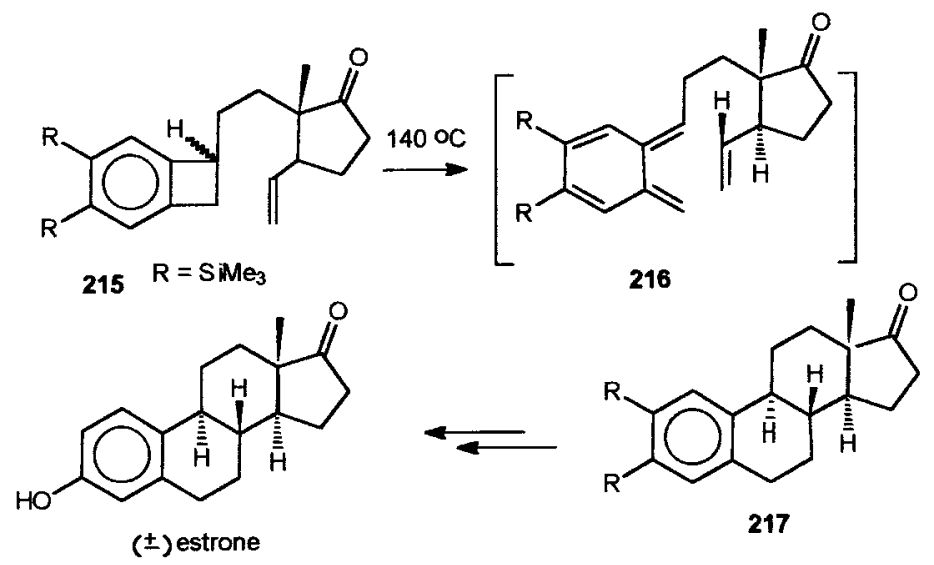

Scheme 124.

Vollhardt's novel approach to estrone utilizes [2+2+2] and $[4+2]$ cycloaddition reactions as the most important steps. The key intermediate, the benzocyclobutene 215, on thermal activation ring opens to the $o$-xylylene 216 which then undergoes a stereospecific intramolecular exo-Diels-Alder cycloaddition to produce the steroidal framework 217 in the correct trans-anti-trans configuration in a remarkably efficient sequence. Subsequent transformations on $\mathbf{2 1 7}$ afford ( \pm )-estrone in an overall yield of $28 \%$ from commercially available 1,5-hexadiyne (Scheme 124). ${ }^{137}$ Another approach to the steroid ring system was derived by Kemetani and his co-workers for the synthesis of ( \pm )-D-homo- estrone 219 from the precursor derivative 218 (Scheme 125). ${ }^{138}$ Oppolzer's approach to the steroidal framework 221 involving the BCB intermediate 220 is shown in Scheme 126. ${ }^{139}$ In a subsequent synthesis, involving compound 222, exclusive formation of the cis-anti-trans product 223 was observed via an endo transition state in contrast to the usual trans-anti-trans sterochemical outcome during IMDA strategy of steroidal molecules (Scheme 127). ${ }^{140}$ This example clearly illustrates how the delicate stereochemical outcome of the IMDA reaction can be influenced by changing the nature of the substitution on the incipient ring $\mathrm{C}$.

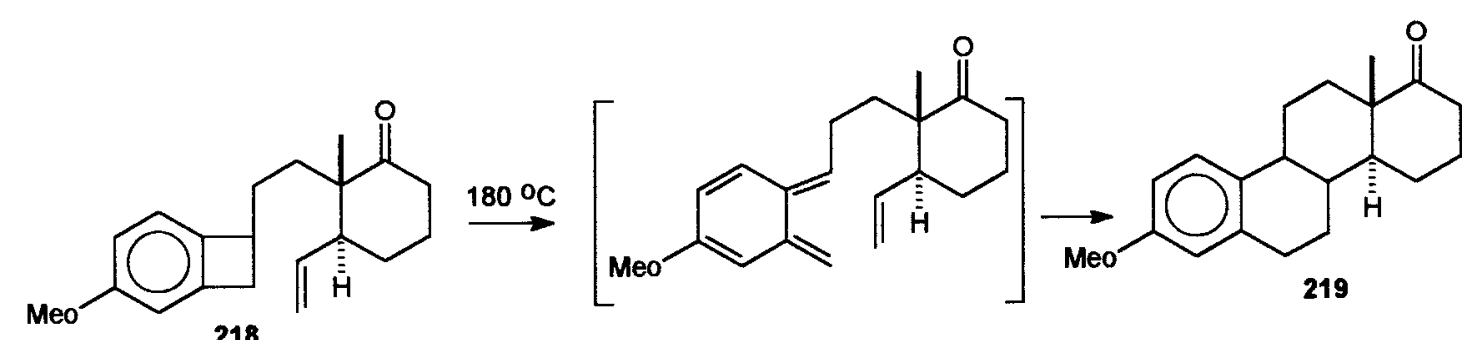

Scheme 125.

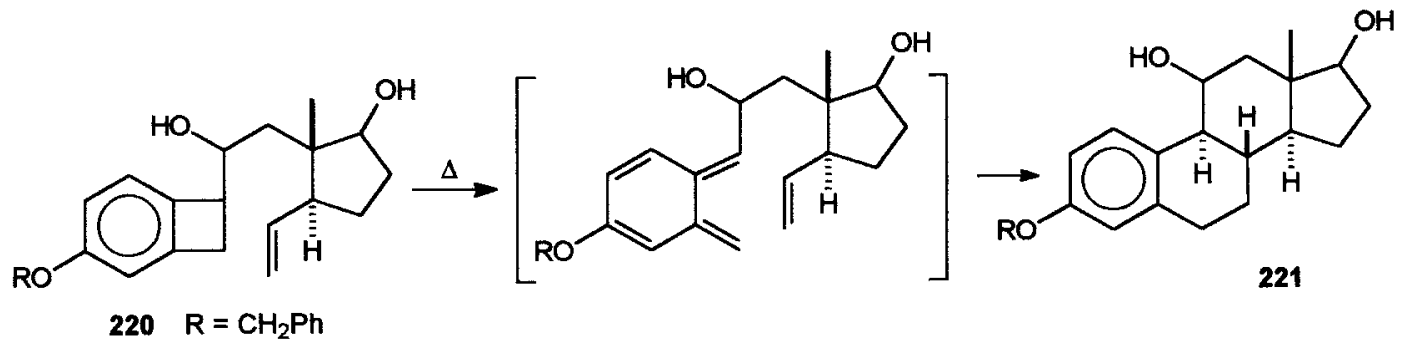




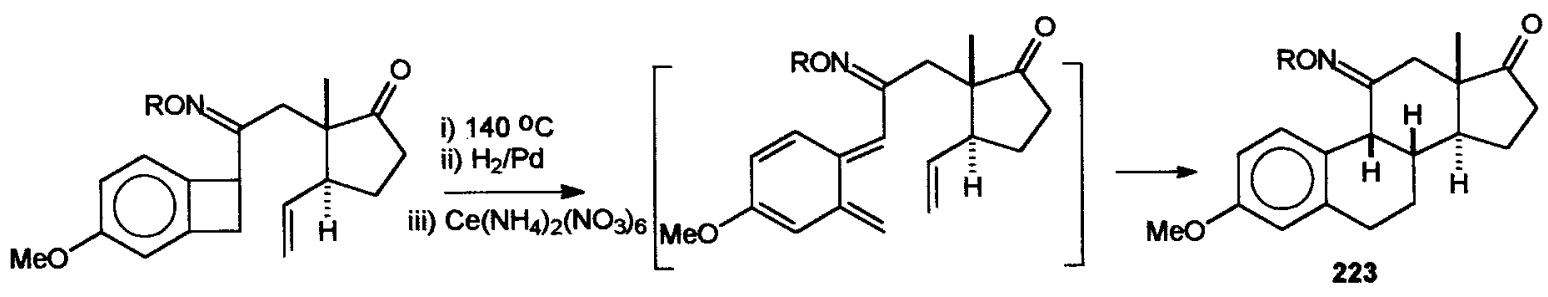

$222 \mathrm{R}=\mathrm{CH}_{2} \mathrm{Ph}$

Scheme 127.<smiles>C=CC1(C)CCC(=O)C1(C)CCC1Cc2cc(OC)ccc21</smiles>

Scheme 128.

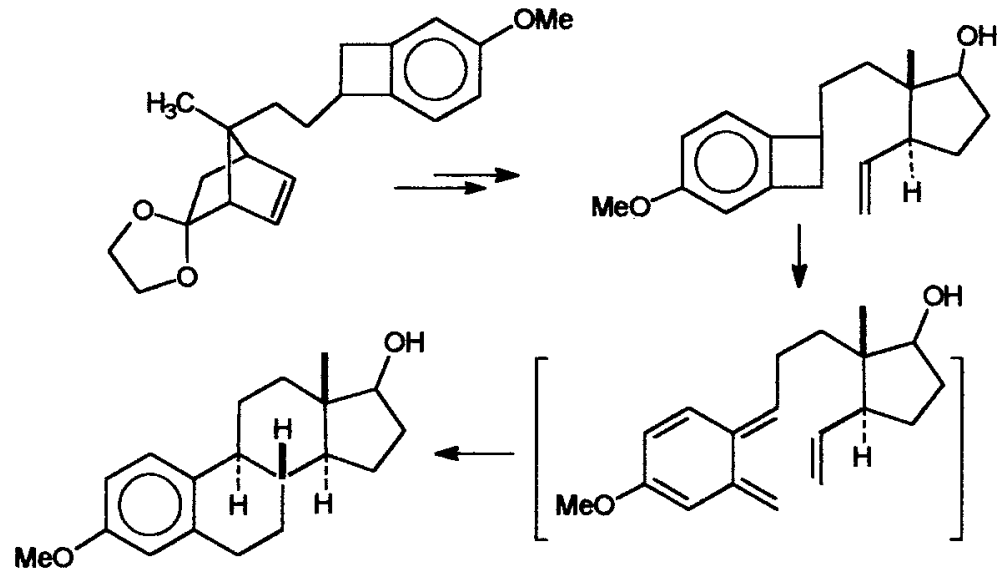

Scheme 129.

Asymmetric synthesis of the estrone derivative 225 involving the key BCB intermediate 224 is shown in Scheme 128. ${ }^{141}$ This intermediate $\mathbf{2 2 4}$ differs from that used in the earlier strategy where the $o$-benzyloxy functionality (i.e.

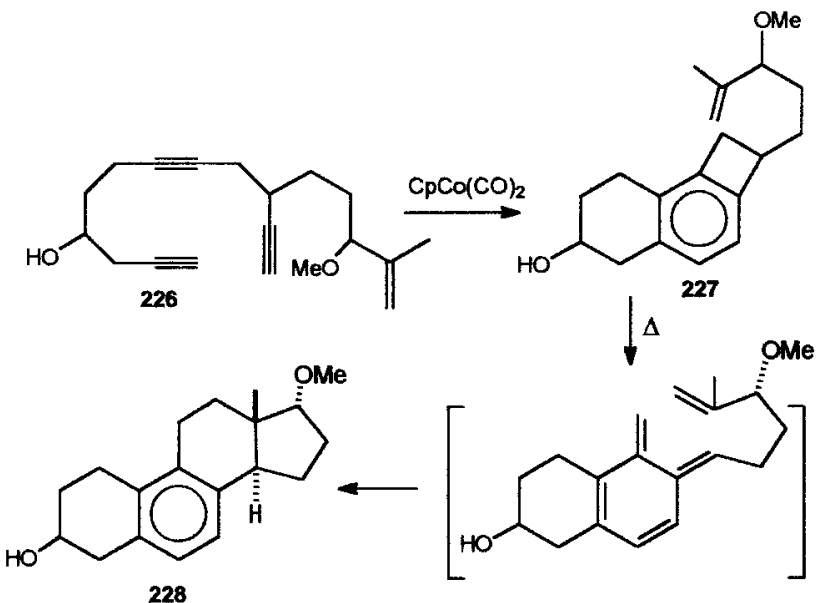

Scheme 130. intermediate 220) is replaced by a carbonyl group and this is sufficient to favor the exo-transition state leading to a trans-anti-trans product. The bicyclo[2.2.1]heptanone building block which has been exploited extensively in the synthesis of many natural products (e.g. prostaglandins) has also found its way into estrone synthesis through intervention with the BCB moiety as reported by Grieco and co-workers. The key transformations leading to the required stereochemistry are shown in Scheme 129.142 Another interesting example involving the intramolecular ene-triyne cyclization of an acyclic precursor 226 to the BCB derivative 227 followed by intramolecular [4+2] cycloaddition to a ring-B aromatic steroid $\mathbf{2 2 8}$ has been reported (Scheme 130). ${ }^{143}$ This approach is unique in the sense that the four rings are all assembled in one step with complete control of the crucial stereochemistry of the $\mathrm{C}-\mathrm{D}$ ring junction.

An extremely simple and short route to the estrone derivative 230 from a 1,3-butadiene derivative has been reported. The key transformation involving the BCB intermediate 229 is shown in Scheme 131. ${ }^{144}$ Recently, a French group has reported an abridged route to a key intermediate in Kametani's synthesis of the steroid derivative 232. This 

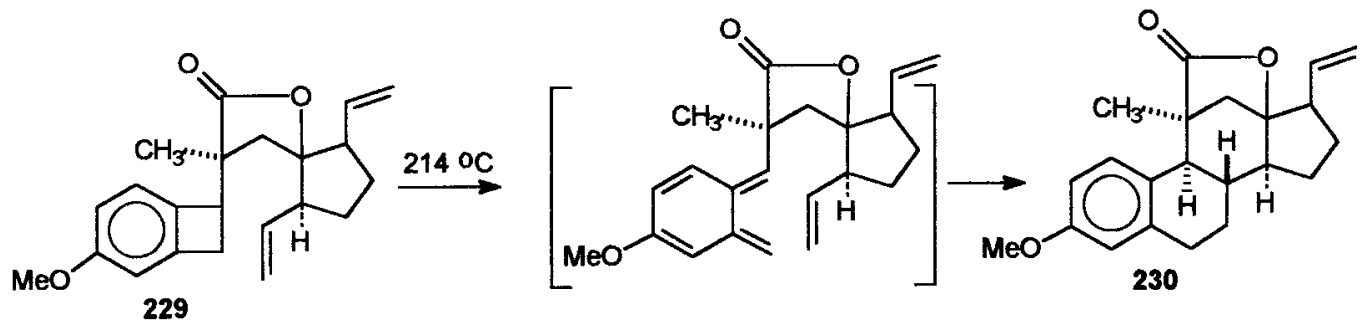

Scheme 131.

strategy involves a Torgov-like reaction of 2-methylcyclopentane-1,3-dione with the BCB intermediate 231 (Scheme 132). ${ }^{145}$ In connection with des-A,B-aromatic steroids, Fukumoto's group has reported an asymmetric synthesis of the tricyclic intermediate 234 starting from the BCB derivative 233 (Scheme 133), ${ }^{146}$ in which a chiral oxathiane system was used as the stereodirecting group. In a related study, the tricyclic intermediate $\mathbf{2 3 6}$ was prepared from the $\mathrm{BCB}$ derivative 235 (Scheme 134). ${ }^{147}$

\subsection{Anthracycline and related quinone synthesis}

Several anthracycline antibiotics such as daunomycin, 4-demethoxydaunomycin and adriamycin have found clinical use in the treatment of various types of cancer and this has stimulated much research into the synthesis of their tetracyclic aglycons. ${ }^{148}$ In this section some examples in which BCB derivatives are employed for the synthesis of anthracycline derivatives are described.

Kametani's group studied the Diels-Alder chemistry of the tetrahydronaphtho-quinone $\mathbf{2 3 8}$ and the 1-cyanobenzocyclobutane derivative $\mathbf{2 3 7}$ to furnish the tetracyclic compound 239 en route to the anthracyclines (Scheme 135). ${ }^{149}$ The cyclobuta $[b]$ anthracene derivative 240 undergoes a facile intermolecular Diels-Alder reaction with various dienophiles (methyl vinyl ketone) to generate the tetracyclic compound $\mathbf{2 4 1}$ related to anthracyclinones (Scheme 136). ${ }^{150}$ The annelated cyclobutane strategy for the generation of $o$-xylylene intermediates gives better yields when compared with the other alternate starting material.

Swenton et al. used metallation strategy to couple the BCB derivative $\mathbf{2 4 2}$ and the sulphone $\mathbf{2 4 3}$ to obtain the tetracyclic

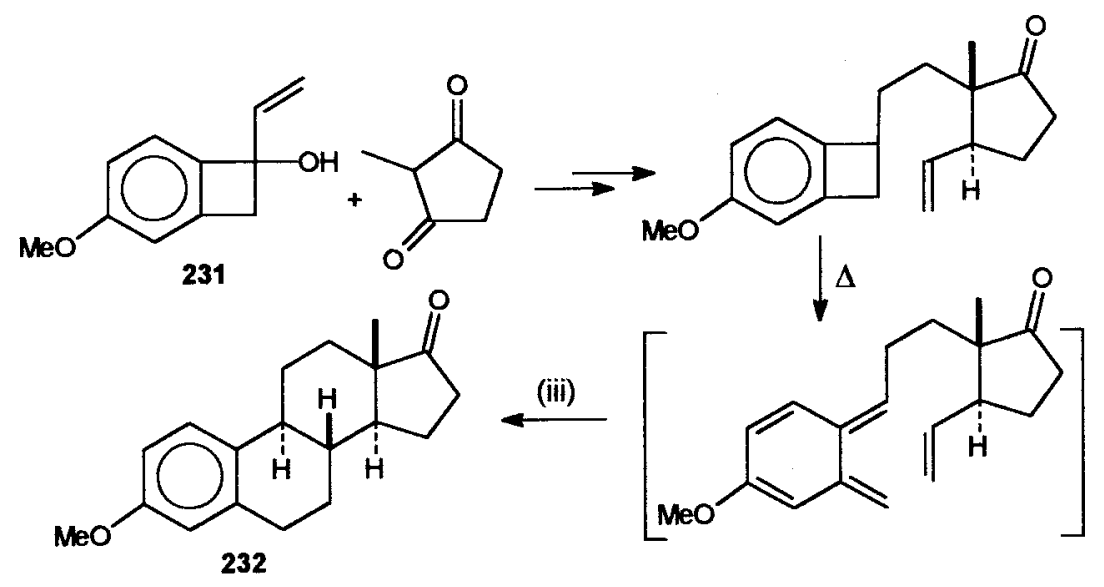

Scheme 132 .

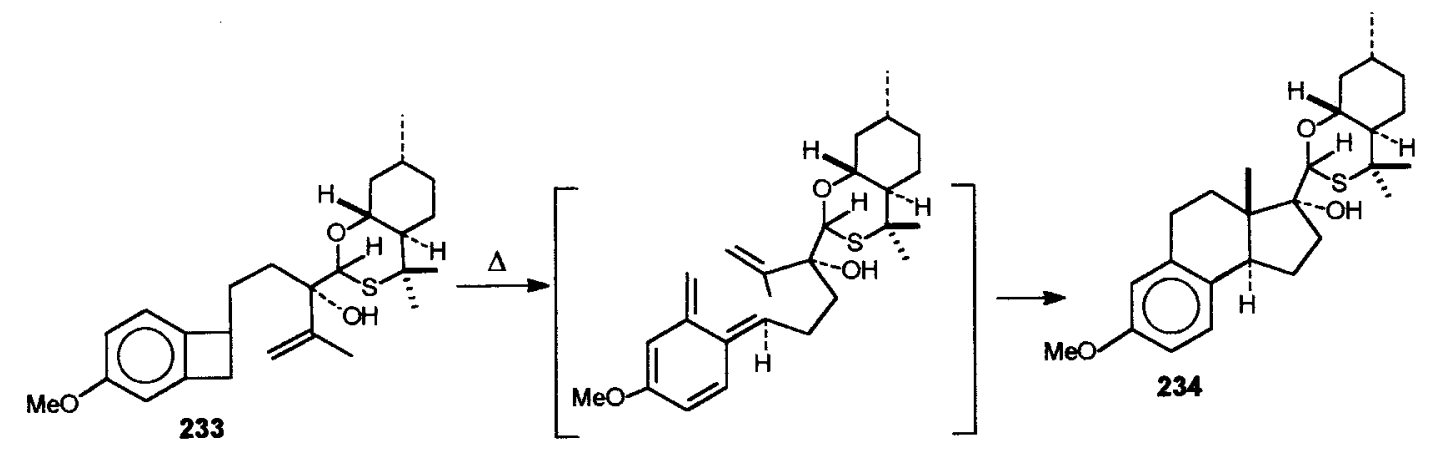

Scheme 133. 


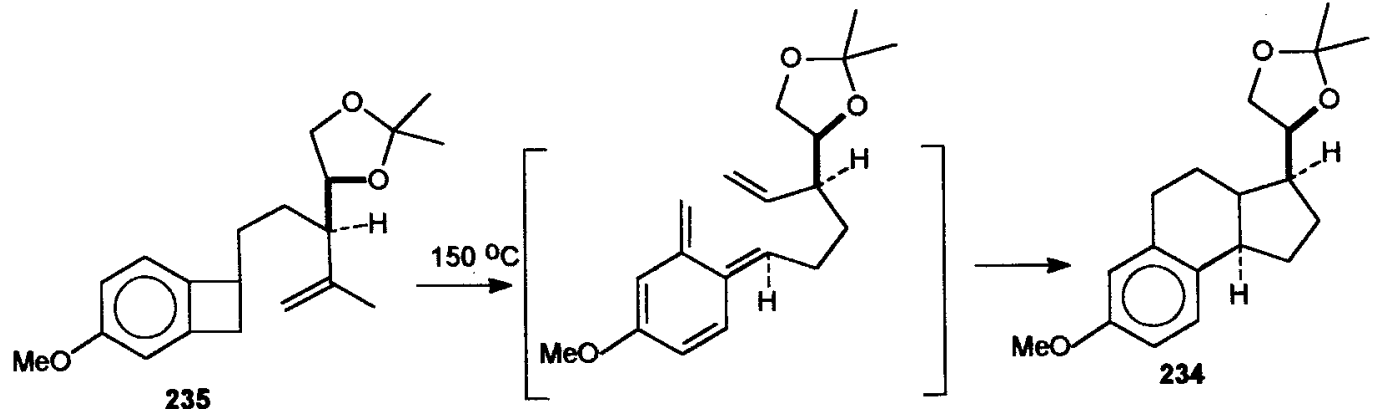

Scheme 134.<smiles>CCOC1=CCC2C(=O)C=CC(=O)C2C1</smiles>

Scheme 135

intermediate 244, suitable for further elaboration (Scheme 137). ${ }^{151}$ A potential anthracycline derivative 247 has been prepared from the benzocyclobutenone $\mathbf{2 4 5}$ and the quinone acetal 246 as starting materials (Scheme 138). ${ }^{152}$ Several conjugated semiquinones such as $\mathbf{2 5 0}$ have been prepared via Diels-Alder strategy using the BCB intermediate 248 and the quinone 249 (Scheme 139). ${ }^{153}$

\subsection{Derivatization of fullerenes}

Functionalization of fullerenes and particularly of $\mathrm{C}_{60}$ for further processing as useful materials has received considerable attention in recent years. $\mathrm{C}_{60}$ has been known to exhibit dienophilic character through the participation of the 6-C double bond in [4+2] cycloadditions. A range of BCBs<smiles></smiles>

Scheme 136.<smiles>COC1(OC)C=CC(=O)C2=C1C1(C2)OCCO1</smiles>

242

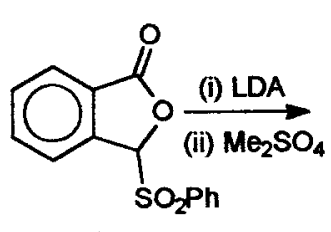

243<smiles>COc1c2c(c(OC)c3c1C(=O)c1ccccc1C3=O)C1(C2)OCCO1</smiles>

24

Scheme 137.

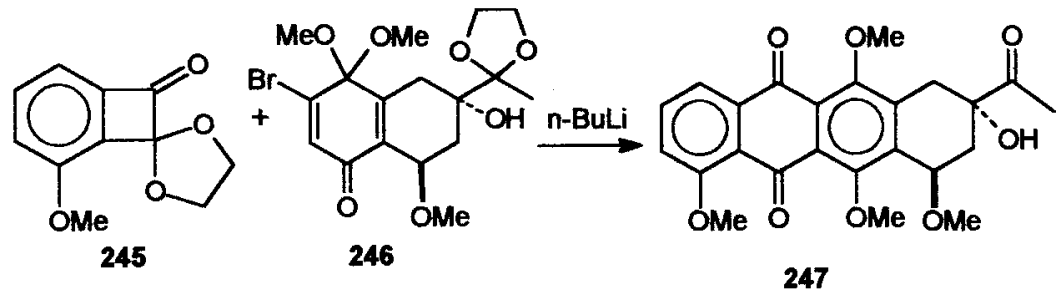




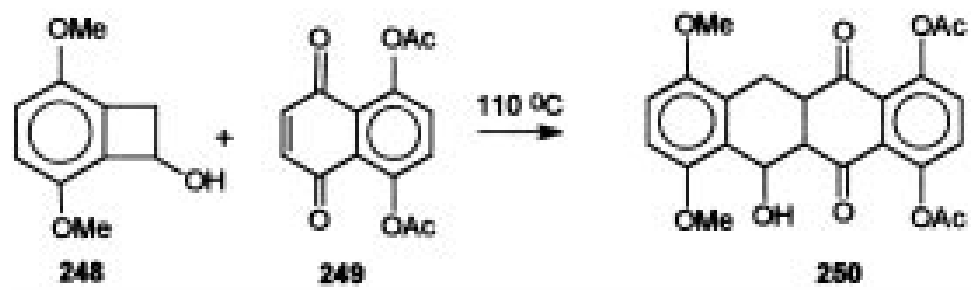

Scheme 139.

have been employed to engage $\mathrm{C}_{60}$ in [4+2] cycloadditions through the corresponding $o$-xylylene intermediates. In most instances $o$-xylylenes were generated by the thermal ring opening of $\mathrm{BCB}$ derivatives or by 1,4-elimination of $\mathrm{Br}_{2}$ from 1,2-bis(bromomethyl)arenes. A number of BCBs and related derivatives that undergo cycloaddition reactions with $\mathrm{C}_{60}$ are shown in Fig. $4 .{ }^{154}$

\subsection{Cyclophane synthesis}

In cyclophanes the close proximity of two benzene rings provides strong interaction of the $\pi$-systems and therefore synthesis of 'phane' systems has attracted considerable attention. Superphane 251, a multibridge $\left[2_{n}\right]$ cyclophane, has been synthesized and BCB and its derivatives play a pivotal role (Scheme 140). ${ }^{155}$ The key to the successful synthesis of this intricate molecule is the multiple deployment of BCB precursors which dimerize through $o$-xylylene intermediates to introduce more than one bridge at a time. Reaction of BCB 1 with the tetrasilylcycloocta-1,5-diyne derivative $\mathbf{2 5 2}$ gave the orthocyclonaphthophane $\mathbf{2 5 3}$ (Scheme 141). ${ }^{156}$

\subsection{Miscellaneous applications of $\mathrm{BCBs}$}

Birch reduction of the BCB derivative 254 is the key step in

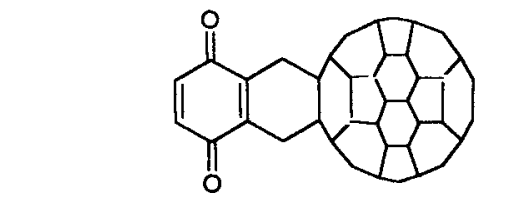

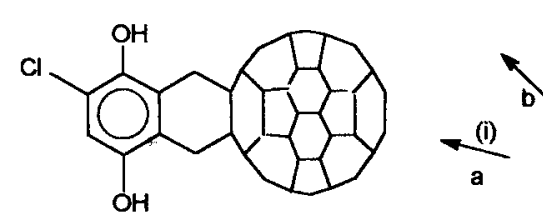

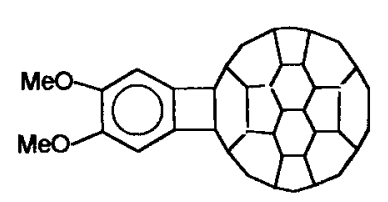

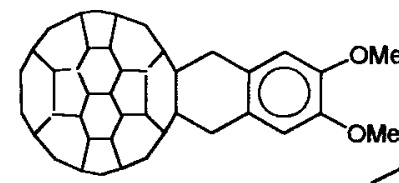
c (iii) (iv)

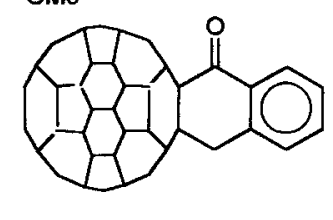

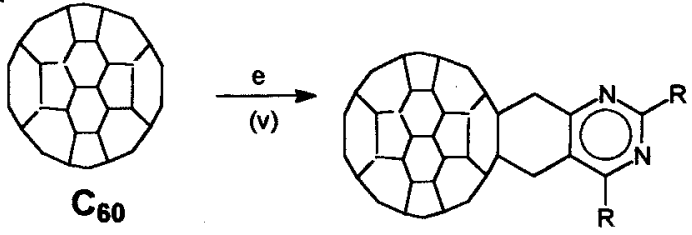

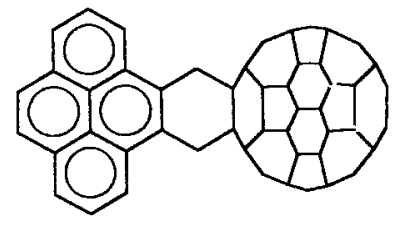

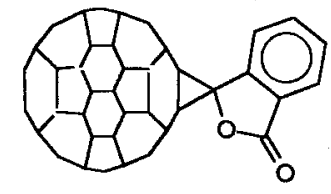

(i)<smiles>c1ccccc1</smiles>

(v)<smiles>[R]c1cccnc1</smiles>

(ii)<smiles>COc1ccc(OC)cc1</smiles>

(vi)<smiles>O=C1Oc2ccccc21</smiles>

DDQ<smiles>c1cncnc1</smiles><smiles>COc1cc2c(cc1[N+]([O-])O[N-])CC2</smiles>

(vii)<smiles>c1cc2ccc3ccc(c4c1CC4)c23</smiles>

(iv)<smiles>OC1Cc2ccccc21</smiles>

(viii)<smiles>COc1ccccc1OC</smiles>

Figure 4. Various Diels-Alder reactions of $\mathrm{C}_{60}$ with $\mathrm{BCB}$ derivatives. 


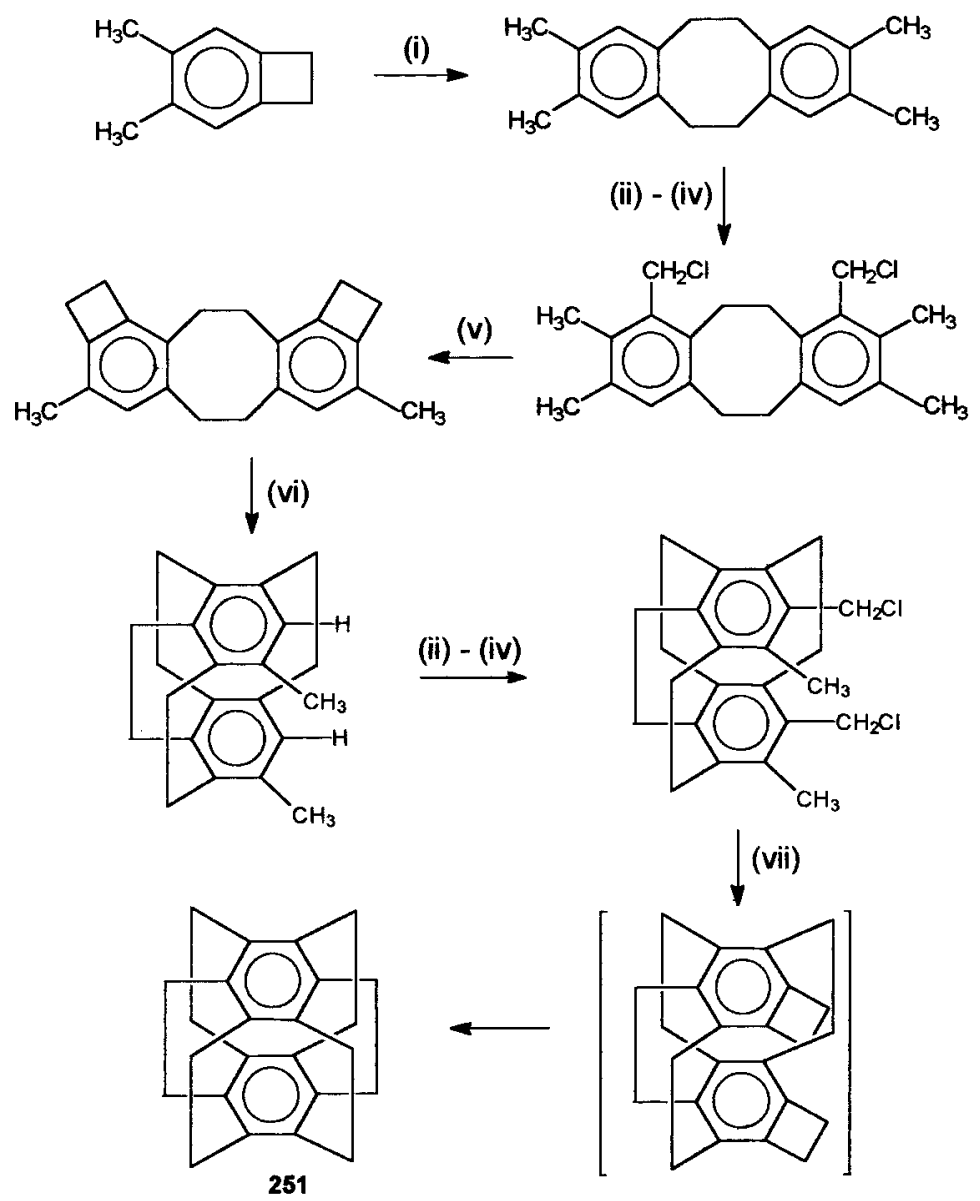

Scheme 140. (i) $400^{\circ} \mathrm{C}, \mathrm{N}_{2}, 1 \mathrm{~atm}$; (ii) $\mathrm{Cl}_{2} \mathrm{CHOCH}_{3}, \mathrm{SnCl}_{4}$; (iii) $\mathrm{NaBH}_{4}$; (iv) $\mathrm{SOCl}_{2}$; (v) $700^{\circ} \mathrm{C}, 10^{-2} \mathrm{~mm}$; (vi) $650^{\circ} \mathrm{C}, 10^{-2} \mathrm{~mm}$.

the synthesis of the cyclobutane sesquiterpene, italicene (Scheme 142). ${ }^{157}$ Similarly, the vitamin $\mathrm{D}_{3}$ precursor 256 has been prepared ${ }^{158}$ from the BCB derivative 255 involving Birch reduction as a key step (Scheme 143). Malacria and co-workers have generated the basic skeleton of tetracyclic diterpenes (phyllocladane and kaurane) via a sequence of consecutive $[3+2],[2+2+2]$ and $[4+2]$ cycloaddition reactions. A carbonyl group at the $\mathrm{C}-12$ position of compound
257 favored the kaurane stereochemistry (58:42), whereas an acetal function at that position led to a highly stereoselective formation of the phyllocladane streochemistry (e.g. 258) (Scheme 144). ${ }^{159}$ In their studies on stemodin synthesis, the same group prepared spiro-substituted BCB derivatives such as $\mathbf{2 5 9}$ and this was shown to undergo a [4+2] cycloaddition reaction via $o$-xylylene intermediates to generate the tetracyclic system 260 (Scheme 145). ${ }^{160}$

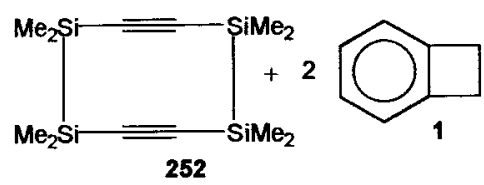

252<smiles>C[As]1c2cc3ccccc3cc2[Si](C)(C)c2cc3ccccc3cc2[As](C)[As]1C</smiles>

$59 \%$

Scheme 141.

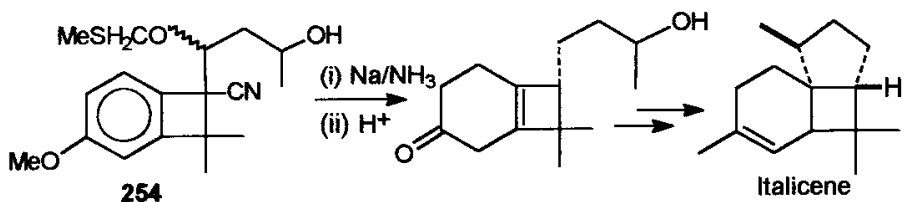




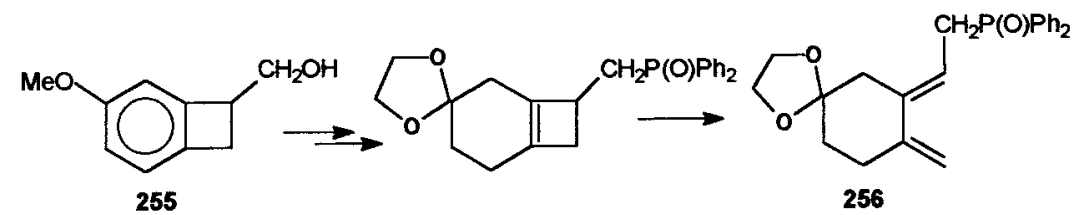

Scheme 143.

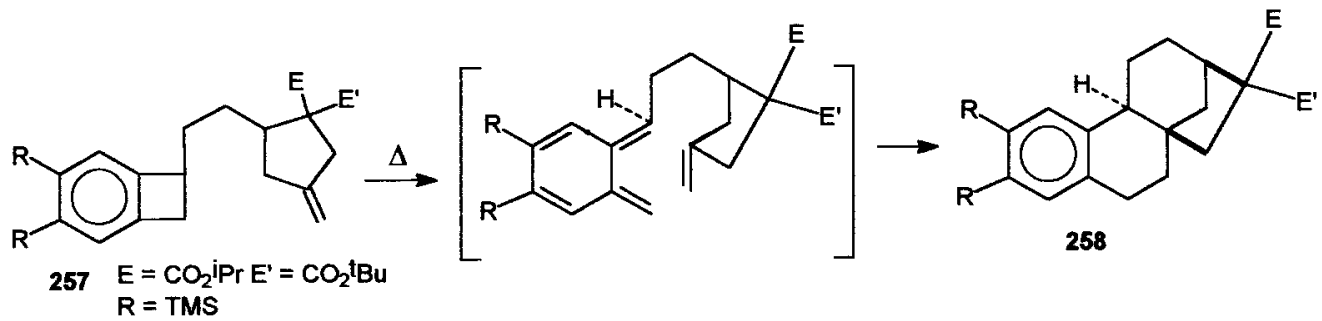

Scheme 144.

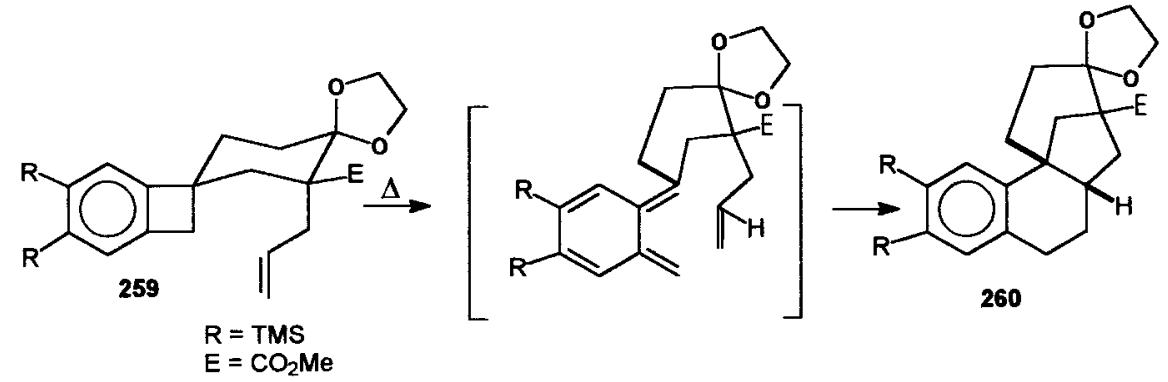

Scheme 145 .

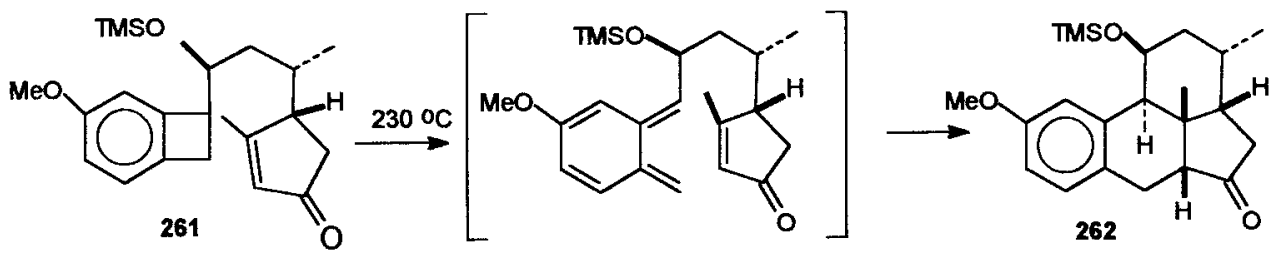

Scheme 146.

IMDA reaction of the $\mathrm{BCB}$ derivative $\mathbf{2 6 1}$ has also been used in the synthetic approach towards the quassinoid ring system 262 (Scheme 146). ${ }^{161}$ Chrome B, a tricyclic terpenoid $p$-benzoquinone $\mathbf{2 6 3}$, isolated from Cordia millenii, was synthesized in a three-step sequence starting from 3,6-dimethoxy BCB 21 and 3-methylcyclohexene-1one 264 employing a Diels-Alder reaction as a key step (Scheme 147). ${ }^{162}$

In a building block approach towards the synthesis of unusual $\alpha$-amino acids, Kotha et al have recently reported the first synthesis of an optically active BCB-based amino acid derivative $\mathbf{2 6 5}$ in a highly diasteroselective manner via a six-step sequence using a Schöllkopf chiral auxiliary (Scheme 148). ${ }^{163}$

\section{Synthesis of natural products containing a BCB unit}

Several interesting natural products having the general structure 266 and incorporation of a BCB moiety have been isolated from Muscari species. ${ }^{164}$<smiles>[R]Cc1cc([R2])c2c(c1)OCC1(C2)C(=O)c2cc([R3])c([R])c([R6])c21</smiles>

There are two reported syntheses of these natural products. The first synthesis starts with the known 1-cyano-4,5methylenedioxybenzocyclobutene 267. Condensation of
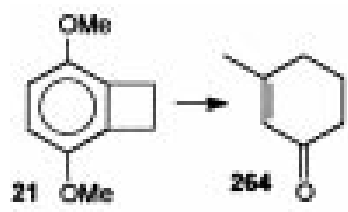<smiles>C=C1CCCC2(C)CC3C(=O)C=CC(=O)C3CC12</smiles>

Scheme 147. (i) $220^{\circ} \mathrm{C}$; (ii) Witting reaction; (iii) CAN. 


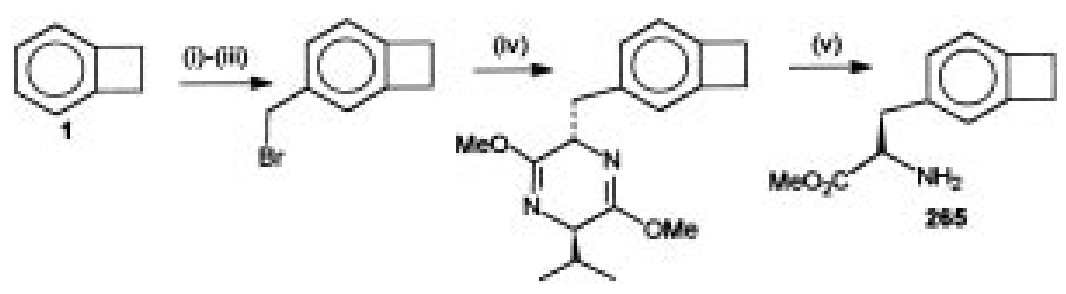

Scheme 148. (i) $\mathrm{TiCl}_{4}, \mathrm{Cl}_{2} \mathrm{CHOCH}_{3}$; (ii) $\mathrm{NaBH}_{4}, \mathrm{MeOH}, \mathrm{NaBr}, \mathrm{BF}_{3} \mathrm{OEt}_{2}, \mathrm{CH}_{3} \mathrm{CN}$; (iv) $n$-BuLi, chiral auxiliary, THF; (v) $1 \mathrm{~N}$ HCl.

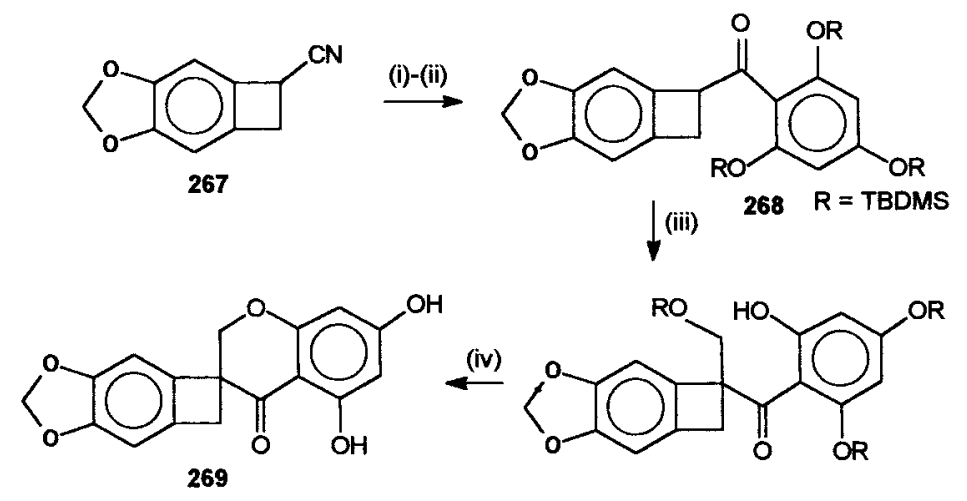

Scheme 149. (i) Phloroglucinol, $\mathrm{HCl}$, ether, $\mathrm{ZnCl}_{2}$; (ii) ${ }^{t} \mathrm{BuMe}_{2} \mathrm{SiCl}, \mathrm{DMF}$, imidazole; (iii) para formaldehyde, $\mathrm{KO} t$ - $\mathrm{Bu}$; (iv) $40 \% \mathrm{HF} / \mathrm{CH} 3 \mathrm{CN}$.

the cyano compound 267 with phloroglucinol under acidic conditions $\left(\mathrm{HCl} / \mathrm{ether} / \mathrm{ZnCl}_{2}\right)$ gave the hydroxy ketone $\mathbf{2 6 8}$. Protection of the hydroxyl functionality as the $t$-butyldimethylsilyl derivative followed by treatment with a catalytic amount of $t$-BuOK and hydrolysis gave the required flavone derivative. Desilylation produced the target $\mathrm{BCB}$ derivative 269 (Scheme 149). ${ }^{165}$

The second synthesis of these natural products, namely of muscomosin 273, is more straightforward and starts with the alkylation of $\mathbf{2 7 0}$ with dibromomethane to give the alkylated product, which was $o$-alkylated with phloroglucinol dibenzyl ether. Hydrolysis of the cyano compound gave 271 which on intramolecular Friedel-Crafts acylation afforded the spiro compound $\mathbf{2 7 2}$ and this was elaborated to muscomosin 273 (Scheme 150). ${ }^{166}$

\section{Concluding remarks}

Certain molecular entities, because of their novel structural features and their interesting reactivity profile, have been the objects of sustained attention of organic chemists. $\mathrm{BCB}$ and its derivatives fall into this category and, for over four decades, their physicochemical characteristics, chemical reactivity and their utility in complex syntheses have been widely explored. In this review, the unusual reactivity pattern of BCBs has been described and their efficacy in complex syntheses by engaging in cycloaddition processes that result in the formation of several $\mathrm{C}-\mathrm{C}$ bonds in single pot reactions has been highlighted. During the past few years, another dimension has been added to BCB chemistry since its derivatives are beginning to find applications in biology and materials science. For example, an interesting

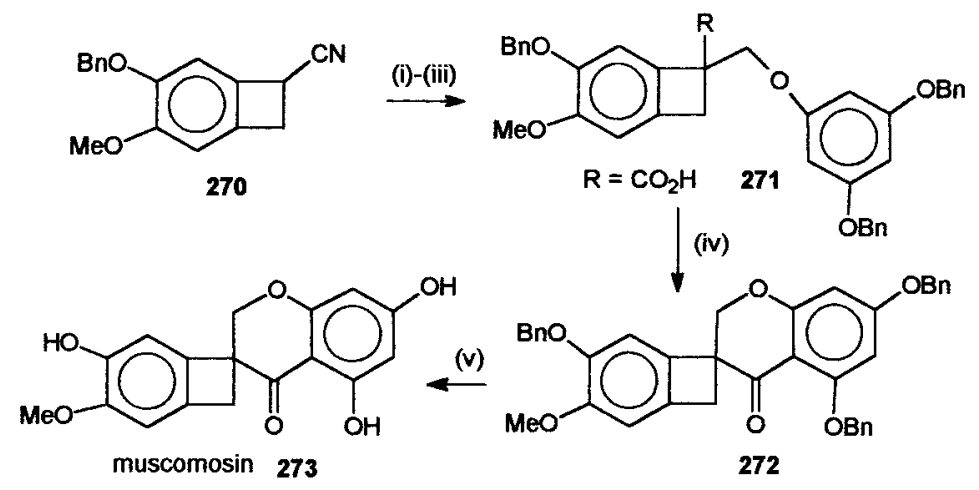

Scheme 150. (i) $\mathrm{Br}\left(\mathrm{CH}_{2}\right)_{2} \mathrm{Br}, \mathrm{NaH} / \mathrm{DMF}, 0^{\circ} \mathrm{C}, 95 \%$; (ii) phloroglucinol dibenzyl ether, $\mathrm{K}_{2} \mathrm{CO}_{3} \mathrm{DMF}, 100^{\circ} \mathrm{C}$ (iii) $\mathrm{K}_{2} \mathrm{CO}_{3}, \mathrm{EtOH}, \Delta$; (iv) $\left(\mathrm{CF}_{3} \mathrm{CO}\right)_{2} \mathrm{O}$, toluene $49 \%$; (v) $\mathrm{Pd}-\mathrm{C}, \mathrm{H}_{2}, 95 \%$. 
BCB derivative $\mathbf{2 7 4}$ was recently listed as a bradycardic agent in a WHO drug information list. ${ }^{167}$ A new family of antitumor agents based on tetrahydrobenzocyclobutacarbazoles such as $\mathbf{2 7 5}$ have been synthesized recently. ${ }^{168} \mathrm{~A}$ synthesis of the 1-benzocyclobutenyl amino acid 276 has been described and this is disclosed as depressant in the patent literature. ${ }^{169}$ Some of the benzocyclobutene-maleimide $\mathrm{AB}$ type monomers (e.g. 277) polymerize to yield exceptionally tough high $T_{\mathrm{g}}$ resins. A lateral covalent bonding in polymers is achieved by incorporating into the molecular backbone a thermally activated cross-linking agent such as 1,2-dihydrocyclobutabenzene-3,6-dicarboxylic acid 278. ${ }^{170}$ With growing importance of the utility of $\mathrm{BCBs}$ in biology, polymer science and materials chemistry, it is hoped that this review may act as catalyst for further exploration of these interesting molecules.<smiles>[Z10]CCN1CCc2cc(OC)c(OC)cc2CC1=O</smiles><smiles>[Z66]CC1(O)c2ccccc2[C@H]2c3c([nH]c4ccccc34)CC21</smiles><smiles>NC1(C(=O)O)Cc2ccccc21</smiles><smiles>O=C(c1ccc(N2C(=O)C=CC2=O)cc1)c1ccc2c(c1)CC2</smiles><smiles>O=C(O)c1ccc(C(=O)O)c2c1CC2</smiles>

\section{Acknowledgements}

S. K. thanks the DST for an SERC visiting fellowship and also for the financial support for our research work over the years.

\section{References}

1. For reviews related to benzocyclobutenes, see: (a) Klundt, I. L. Chem. Rev. 1970, 70, 471. (b) Kametani, T.; Fukumoto, K. Acc. Chem. Res. 1976, 9, 319. (c) Thummel, R. P. Acc. Chem. Res. 1980, 13, 70. (d) Gandhi, P. J. Sci. Ind. Res.(India). 1982, 495. (e) Wada, Y.; Tago, T.; Nishimura, J. J. Synth. Org. Chem. Jpn 1992, 50, 616. (f) Michellys, P.-Y.; Pellissier, H.; Santelli, M. Org. Prep. Proced. Int. 1996, 28, 545.

2. Finkelstein, H. Doctoral Dissertation, University of Strassburg, 1909; Finkelstein, H. Chem. Ber. 1910, 43, 1528.

3. Finkelstein, H. Chem. Ber. 1959, 92, xxxvii.

4. Cava, M. P.; Napier, D. R. J. Am. Chem. Soc. 1956, 78, 500.

5. Jensen, F. R.; Coleman, W. E. J. Am. Chem. Soc. 1958, 80, 6149.
6. Huisgen, R.; Seidl, H. Tetrahedron Lett. 1964, 3381.

7. Woodword, R. B.; Hoffmann, R. Conservation of Orbital Symmetry; Verlag Chemie: Weinheim, 1970.

8. Oppolzer, W. Synthesis 1978, 793; Charlton, J. L.; Alauddin, M. M. Tetrahedron 1987, 43, 2873; McCullough J. J. Acc. Chem. Res. 1980, 13, 270; Martin, N.; Seoane, C.; Hanack, M. Org. Prep. Proced. Int. 1991, 23, 237; Chou, T. S. Rev. Heteroatom. Chem. 1993, 8, 65; Segura, J. L.; Martin, N. Chem. Rev. 1999, 99, 3199.

9. Shepherd, M. K. Cyclobutarenes; Elsevier: Oxford, 1991.

10. Toda, F.; Garratt, P. Chem. Rev. 1992, 92, 1685.

11. Nemeto, H.; Fukumoto, K. Tetrahedron 1998, 54, 5425.

12. Kirchhoff, R. A.; Bruza, K. J. Chemtech 1993, 22; Kirchhoff, R. A.; Bruza, K. J. Prog. Polym. Sci. 1993, 18, 85; Kirchhoff, R. A.; Bruza, K. J. Adv. Polym. Sci. 1994, 117, 3.

13. Schulman, J. M.; Disch, R. L. J. Am. Chem. Soc. 1993, 115, 11153.

14. Skancke, A.; Skancke, P. N. Acta Chem. Scand. Ser. A 1988 , $42,428$.

15. For some related papers in this aspect see: Koch, W.; EckertMaksic, M.; Maksic, Z. B. Int. J. Quantum Chem. 1993, 48, 319; Maksic, Z. B.; Eckert-Maksic, M.; Kovacek, D.; Margetic, D. J. Mol. Struct. (Theochem) 1992, 260, 241.

16. Sakaizumi, T.; Katoh, F.; Ohashi, O.; Yamaguchi, I. J. Mol. Spectrosc. 1993, 159, 112.

17. Ou, M.-C.; Chu, S-Y. J. Phys. Chem. 1994, 98, 1087.

18. Davies, A. G.; Ng, K. M. J. Chem. Soc., Perkin Trans. 2 1992, 1857; Avila, D. V.; Davies, A. G.; Li, E. R.; Ng, K. M. J. Chem. Soc., Perkin Trans. 2 1993, 355.

19. (a) Boese, R.; Bläser, D. Angew. Chem., Int. Ed. Engl. 1988, 27, 304; Lawarence, J. L.; McDonald, S. G. G. Acta Crystallogr. 1969, B25, 978. (b) Stanger, A.; Ashkenazi, N.; Shachter, A.; Bläser, D.; Stellberg, P.; Boese, R. J. Org. Chem. 1996, 61, 2549. (c) Allen, F. H.; Trotter, J. J. Chem. Soc. B 1970, 916. (d) Hardgrove, G. L.; Templeton, L. K.; Templeton, D. H. J. Phys. Chem. 1968, 72, 668. (e) Deeter, G. A.; Venkataraman, D.; Kampf, J. W.; Moore, J. S. Macromolecules 1994, 27, 2647. (f) Crawford, J. L.; Marsh, R. E. Acta Crystallogr. 1973, B29, 1238. (g) Toda, F.; Tanaka, K.; Watanabe, M.; Tamura, K.; Miyahara, I.; Nakai, T.; Hirotsu, K. J. Org. Chem. 1999, 64, 3102. (h) Thummel, R. P. Croat. Chem. Acta 1980, 53, 659. (i) Ianelli, S.; Nardelli, M. Acta Crystallogr. 1992, C48, 1730.

20. Sanders, A.; Giering, W. P. J. Org. Chem. 1973, 38, 3055.

21. Hart, H.; Hartlage, J. A.; Fish, R. W.; Rafos, R. R. J. Org. Chem. 1966, 31, 2244.

22. Schiess, P.; Heitzmann, M.; Rutschmann, S.; Stäheli, R. Tetrahedron Lett. 1978, 19, 4569.

23. Walker, K. A.; Markoski, L. J.; Moore, J. S. Synthesis 1992, 1265.

24. So, Y.-H. Ind. Eng. Chem. Res. 1993, 32, 952.

25. Schiess, P. Thermochim. Acta 1987, 112, 31.

26. Chou, C.-H.; Wu, C.-C.; Chen, W.-K. Tetrahedron Lett. 1995, 36, 5065.

27. (a) Schiess, P.; Heitzmann, M. Helv. Chim. Acta 1978, 61, 844. (b) Hart, H.; Jeffares, M.; Teuerstein, A.; Ward, D. L. J. Am. Chem. Soc. 1978, 100, 8012.

28. Lenihan, B. D.; Shechter, H. J. Org. Chem. 1998, 63, 2086.

29. Parham, W. E.; Jones, L. D.; Sayed Y. A. J. Org. Chem. 1976, 41, 1184; Bradsher, C. K.; Edgar, K. J. J. Org. Chem. 1981, 46, 4600; Bradsher, C. K.; Hunt, D. A. J. Org. Chem. 1981, 46, 4608. 
30. Bradsher, C. K.; Hunt, D. A. Org. Prep. Proced. Int. 1978, 10, 267; Sardessai, M. S.; Abramson, H. N. Org. Prep. Proced. Int. 1991, 23, 419 and references cited therein.

31. Buchwald, S. L.; Lucas, E. A.; Dewan, J. C. J. Am. Chem. Soc. 1987, 109, 4396.

32. Aidhen, I. S.; Ahuja, J. R. Tetrahadron Lett. 1992, 33, 5431.

33. Dhawan, K. L.; Gowland, B. D.; Durst, T. J. Org. Chem. 1980, 45, 922.

34. Aidhen, I. S.; Narasimhan, N. S. Ind. J. Chem. 1993, 32B, 234; Kobayashi, K.; Kawakita, M.; Mannami, T.; Konishi, H. Tetrahedron Lett. 1995, 36, 733; Kobayashi, K.; Kawakita, M.; Uchida, M.; Nishimura, K.; Mannami, T.; Irisawa, S.; Morikawa, O.; Konishi, H. J. Org. Chem. 1999, 64, 3557.

35. Garrett, J. M. Tetrahedron Lett. 1969, 191.

36. Flynn, C. R.; Michl, J. J. Am. Chem. Soc. 1974, 96, 3280.

37. Wada, Y.; Tago, T.; Sugata, K.; Nishimura, J. J. Org. Chem. 1992, 57, 5955.

38. Hoffmann, N.; Pete, J.-P. Tetrahedron Lett. 1996, 37, 2027.

39. Kessar, S. V.; Singh, T. V.; Narula, M.; Singh, N. P.; Trehan, I. R. Ind. J. Chem. 1985, 24B, 10; Sato, M.; Suzuki, T.; Morisawa, H.; Fujita, S.; Inukai, N.; Kaneko, C. Chem. Pharm. Bull. Jpn 1987, 35, 3647.

40. Kanao, Y.; Iyoda, M.; Oda, M. Tetrahedron Lett. 1983, 24, 1727; Iyoda, M.; Yamauchi, T.; Oda, M. J. Chem. Soc., Chem. Commun. 1986, 303.

41. Wilson, R. M.; Patterson, W. S.; Austen, S. C.; Ho, D. M.; Bauer, J. A. K. J. Am. Chem. Soc. 1995, 117, 7820.

42. Yoshioka, M.; Arai, M.; Nishizawa, K.; Hasegawa, T. J. Chem. Soc., Chem. Commun. 1990, 374; Yoshioka, M.; Momose, S.; Nishizawa, K.; Hasegawa, T. J. Chem. Soc., Perkin Trans. 1 1992, 499; Yoshioka, M.; Miyazoe, S.; Hasegawa, T. J. Chem. Soc., Chem. Commun. 1992, 418; Coll, G.; Costa, A.; Deya, P. M.; Saa, J. M. Tetrahedron Lett. 1991, 32, 263; Cava, M. P.; Litle, R. L.; Napier, D. R. J. Am. Chem. Soc. 1958, 80, 2257.

43. Cava, M. P.; Spangler, R J. J. Am. Chem. Soc. 1967, 89, 4550.

44. Leinweber, D.; Butenschon, H. Tetrahedron Lett. 1997, 38, 6385.

45. Netto-Ferreira, J. C.; Wintgens, V.; Scaiano, J. C. Tetrahedron Lett. 1989, 30, 6851.

46. Higuchi, H.; Otsubo, T.; Ogura, F.; Yamaguchi, H.; Sakata, Y.; Misumi, S. Bull. Chem. Soc. Jpn 1982, 55, 182 and references cited therein.

47. Simpkins, N. S. Sulphones in Organic Synthesis; Pergamon: Oxford, 1990.

48. Carruthers, W. Cycloaddition Reactions in Organic Synthesis; Pergamon: Oxford, 1990.

49. Gray, R.; Harruff, L. G.; Peterson, J. K. J.; Boekelheide, V. J. Am. Chem. Soc. 1978, 100, 2893.

50. Shozda, R. J.; Putnam, R. E. J. Org. Chem. 1962, 27, 1557.

51. Thummel, R. P. J. Chem. Soc., Chem. Commun. 1974, 899; Heilbronner, E.; Kovac, B.; Nutakul, W.; Taggart, A. D.; Thummel, R. P. J. Org. Chem. 1981, 46, 5279.

52. Schmidt, A. H.; Kunz, C. Synthesis 1991, 78; Schmidt, A. H.; Kunz, C.; Malmbak, M.; Zylla, J. Synthesis 1994, 422.

53. Kessar, S. V. In Comprehensive Organic Synthesis; Trost, B. M., Ed.; Pergamon: Oxford, 1991; Vol. 4, 483pp; Wasserman, H. H.; Solodar, J. J. Am. Chem. Soc. 1965, 87, 4002.

54. Hosoya, T.; Hasegawa, T.; Kuriyama, Y.; Matsumoto, T.; Suzuki, K. Synlett 1995, 177.
55. Kametani, T.; Kajiwara, M.; Fukumoto, K. Tetrahedron 1974, 30, 1053; Iwao, M. J. Org. Chem. 1990, 55, 3622.

56. Vollhardt, K. P. C. Angew. Chem., Int. Ed. Engl. 1984, 23, 539.

57. Deeken, J. S.; Farona, M. F. Polym. Bull. 1992, 29, 295.

58. McNichols, A. T.; Stang, P. J. Synlett 1992, 971.

59. Muller, P.; Bernardinelli, G.; Jacquier, Y.; Ricca, A. Helv. Chim. Acta. 1989, 72, 1618.

60. Kagabu, S.; Saito, K. Tetrahedron Lett. 1988, 29, 675.

61. Iskander G. M.; Stansfield, F. J. Chem. Soc. 1965, 1390; Birch, A. J.; Brown, J. M.; Stansfield, F. J. Chem. Soc. 1964, 5343.

62. Ter Borg, A. P.; Bickel, A. F. Recueil 1961, 80, 1217.

63. Ezcurra, J. E.; Moore, H. W. Tetrahedron Lett. 1993, 34, 6177.

64. Toda, F.; Tanaka, K.; Sano, I.; Isozaki, T. Angew. Chem., Int. Ed. Engl. 1994, 33, 1757.

65. Inanaga, J.; Sugimoto, Y.; Hanamoto, T. Tetrahedron Lett. 1992, 33, 7035.

66. Roedig, A.; Ganns, E. M.; Henrich, C.; Schnutenhaus, H. Liebigs. Ann. Chem. 1981, 1674.

67. Edwards, J. P.; Krysan, D. J.; Liebeskind, L. S. J. Org. Chem. 1993, 58, 3942.

68. Peek, M. E.; Rees, C. W.; Starr, R. C. J. Chem. Soc. C 1974, 1260; Pearce, D. S.; Lee, M.-S.; Moore, H. W. J. Org. Chem. 1974, 39, 1362.

69. Warrener, R. N.; Pitt, I. G.; Russell, R. A. Aust. J. Chem. 1993, 46, 1009.

70. Marchand, A. P.; Chou, T.-C. J. Chem. Soc., Perkin Trans. 1 1973, 1948.

71. Bradley, J. C.; Durst, T. J. Org. Chem. 1991, 56, 5459.

72. Bocelli, G.; Catellani, M.; Chiusoli, G. P. J. Orgmet. Chem. 1984, 279, 225.

73. Fitzgerald, J. J.; Pagano, A. R.; Sakoda, V. M.; Olofson, R. A. J. Org. Chem. 1994, 59, 4117.

74. Fitzgerald, J. J.; Michael, F. E.; Olofson, R. A. Tetrahedron Lett. 1994, 35, 9191.

75. Fitzgerald, J. J.; Drysdale, N. E.; Olofson, R. A. J. Org. Chem. 1992, 57, 7122; Hussain, A.; Parrick, J. Tetrahedron Lett. 1983, 24, 609.

76. Brands, M.; Wey, H. G.; Butenschon, H. J. Chem. Soc., Chem. Commun. 1991, 1541.

77. Bertelli, D. J.; Crews, P. J. Am. Chem. Soc. 1968, 90, 3889.

78. Matusumoto, T.; Hamura, T.; Kuriyama, Y.; Suzuki, K. Tetrahedron Lett. 1997, 38, 8985.

79. Maercker, A.; Berkulin, W.; Schiess, P. Angew. Chem., Int. Ed. Engl. 1983, 22, 246.

80. Maercker, A.; Berkulin, W.; Schiess, P. Tetrahedron Lett. 1984, 25, 1701.

81. Horner, L.; Schmelzer, H. G.; Thompson, B. Chem. Ber. 1960, 93, 1774.

82. Olah, G. A.; Head, N. J.; Rasul, G.; Prakash, G. K. S. J. Am. Chem. Soc. 1995, 117, 875.

83. Lloyd, J. B. F.; Ongley, P. A. Tetrahedron 1965, 21, 245; Lloyd, J. B. F.; Ongley, P. A. Tetrahedron 1964, 20, 2185; Eaborn, C.; Najam, A. A.; Walton, D. R. M. J. Chem. Soc., Perkin Trans. 1 1972, 2481.

84. Thomas, P. J.; Pews, R. G. Synth. Commun. 1991, 21, 2335.

85. Thomas, P. J.; Pews, R. G. Synth. Commun. 1993, 23, 505.

86. Hahn, S. F.; Martin, S, J.; McKelvy, M. L. Macromolecules 1992, 25, 1539; Hahn, S. F.; Martin, S. J.; McKelvy, M. L.; Patrick, D. W. Macromolecules 1993, 26, 3870; Endo, T.; 
Koizumi, T.; Takata, T.; Chino, K. J. Polym. Sci., Part A: Polym. Chem. 1995, 33, 707.

87. D’Andrea, S. V.; Freeman, J. P.; Szmuszkovicz, J. J. Org. Chem. 1990, 55, 4356.

88. Toda, M.; Okada, K.; Oda, M. Tetrahedron Lett. 1988, 29 , 2329.

89. Luo, J.; Hart, H. J. Org. Chem. 1987, 52, 4833.

90. Shimada, S.; Osoda, K.; Narasaka, K. Bull. Chem. Soc. Jpn 1993, 66, 1254.

91. Charlton, J. L.; Koh, K. Synlett 1990, 333; Charlton, J. L.; Plourde, G. L.; Koh, K.; Secco, A. S. Can. J. Chem. 1990, 68, 2022.

92. Andersen, N. G.; Maddaford, S. P.; Keay, B. A. J. Org. Chem. 1996, 61, 2885.

93. Craig, D.; Robson, M. J.; Shaw, S. J. Synlett 1998, 1381.

94. Shishido, K.; Yamashita, A.; Hiroya, K.; Fukumoto, K.; Kametani, T. Tetrahedron Lett. 1989, 30, 111.

95. Shishido, K.; Yamashita, A.; Hiroya, K.; Fukumoto, K. J. Chem. Soc., Perkin Trans. 1 1990, 469.

96. Hickman, D. N.; Wallace, T. W.; Wardleworth, J. M. Tetrahedron Lett. 1991, 32, 819.

97. Shishido, K.; Hiroya, K.; Fukumoto, K.; Kametani, T. Heterocycles 1989, 28, 39.

98. Turro, N. J.; Zhang, Z.; Trahanovsky, W. S.; Chou, C. H. Tetrahedron Lett. 1988, 29, 2543.

99. Takahashi, Y.; Kochi, J. K. Chem. Ber. 1988, 121, 253.

100. Kobayashi, K.; Itoh, M.; Suginome, H. Tetrahedron Lett. 1987, 28, 3369.

101. Kobayashi, K.; Itoh, M.; Sasaki, A.; Suginome, H. Tetrahedron 1991, 47, 5437.

102. Murata, S.; Yamamoto, T.; Tomioka, H. J. Am. Chem. Soc. 1993, 115, 4013.

103. Boyd, D. R.; Sharma, N. D.; Stevenson, P. J.; Chima, J.; Gray, D. J.; Dalton, H. Tetrahedron Lett. 1991, 32, 3887.

104. Swanson, P. E. Appl. Environ. Microbiol. 1992, 58, 3404.

105. Hosoya, T.; Kuriyama, Y.; Suzuki, K.Synlett 1995, 635.

106. Kametani, T.; Toya, T.; Ueda, K.; Tsubuki, M.; Honda, T. J. Chem. Soc., Perkin Trans. 1 1988, 2433.

107. Carre, M.-C.; Gregoire, B.; Caubere, P. J. Org. Chem. 1984, 49, 2050.

108. Whitlock Jr., H. W.; Fuchs Jr., P. Tetrahedron Lett. 1968 , 1453.

109. Kündig, E. P.; Perret, C. Helv. Chim. Acta 1981, 64, 2606.

110. Barton, J. W.; Howard, J. A. K.; Shepherd, M. K.; Stringer, A. M. J. Chem. Soc., Perkin Trans. 1 1987, 2443.

111. O'Leary, M. A.; Wege, D. Tetrahedron 1981, 37, 800.

112. Thummel, R. P.; Chayangkoon, P. J. Org. Chem. 1983, 48, 596.

113. Kawase, T.; Ohnishi, Y.; Oda, M. J. Chem. Soc., Chem. Commun. 1991, 702.

114. Shishido, K.; Hiroya, K.; Yamashita, A.; Tokunaga, Y.; Fukumoto, K. Heterocycles 1990, 30, 253.

115. Rieke, R. D.; Bales, S. E.; Hudnall, P. M.; Meares, C. F. J. Am. Chem. Soc. 1970, 92, 1418.

116. Bauld, N. L.; Farr, F. J. Am. Chem. Soc. 1969, 91, 2788.

117. Hillard III, R. L.; Vollhardt, K. P. C. J. Am. Chem. Soc. 1976, 98, 3579 .

118. Iyoda, M.; Kuwatani, Y.; Yamauchi, T.; Oda, M. J. Chem. Soc., Chem. Commun. 1988, 65; Cheng, S. K. T.; Wong, H. N. C. Synth. Commun. 1990, 20, 3053.

119. Sprecher, G. V.; Winkler, T. Tetrahedron Lett. 1986, 27, 4285.
120. Adam, G.; Andrieux, J.; Plat, M. Tetrahedron Lett. 1981, 22, 3181.

121. Wey, H. G.; Butenschön, H. Chem. Ber. 1990, 123, 93; Schiess, P.; Rutschmann, S.; Toan, V. V. Tetrahedron Lett. 1982, 23, 3669.

122. Roedig, A.; Ganns, E. M.; Henrich, C. Tetrahedron 1983, 39, 645.

123. Kündig, E. P.; Perret, C.; Rudolph, B. Helv. Chim. Acta 1990, 73, 1970.

124. Krohn, K.; Rieger, H.; Broser, E.; Schiess, P.; Chen, S.; Strubin, T. Liebigs Ann. Chem. 1988, 943.

125. Staab, H. A.; Ipaktschi, J. Chem. Ber. 1968, 101, 1457; Miller, R. D.; Kirchmeyer, S. J. Org. Chem. 1993, 58, 90.

126. Brands, M.; Bruckmann, J.; Krüger, C.; Butenschön, H. J. Chem. Soc., Chem. Commun. 1994, 999.

127. Liebskind, L. S.; Baysdon, S. L.; South, M. S.; Blount, J. F. J. Orgmet. Chem. 1980, 202, C73.

128. Oppolzer, W.; Keller, K. J. Am. Chem. Soc. 1971, 93, 3836; Oppolzer, W. Tetrahedron Lett. 1974, 15, 1001; Oppolzer, W. J. Am. Chem. Soc. 1971, 93, 3833; Oppolzer, W. Angew. Chem., Int. Ed. Engl. 1972, 11, 1031; Oppolzer, W. Angew. Chem., Int. Ed. Engl. 1972, 11, 1108; Oppolzer, W.; Robbiani, C. Helv. Chim. Acta. 1983, 66, 1119.

129. Kametani, T.; Suzuki, T.; Takahashi, K.; Fukumoto, K. Heterocycles 1974, 12, 9.

130. Kametani, T.; Yukawa, H.; Suzuki, Y.; Yamaguchi, R.; Honda, T. Heterocycles 1984, 22, 1067.

131. Kametani, T.; Suzuki, Y.; Honda, T. Chem. Pharm. Bull. 1986, 34, 4971; Kametani, T.; Suzuki, Y.; Honda, T. Heterocycles 1985, 23, 563; Kametani, T.; Suzuki, Y.; Honda, T. Heterocycles 1985, 23, 305.

132. Shishido, K.; Hiroya, K.; Fukumoto, K.; Kametani, T.; Kabuto, C. J. Chem. Soc., Perkin Trans. 1 1989, 1443.

133. Shishido, K.; Komatsu, H.; Fukumoto, K.; Kametani, T. Heterocycles 1989, 28, 43; Shishido, K.; Shitara, E.; Komatsu, H.; Hiroya, K.; Fukumoto, K.; Kametani, T. J. Org. Chem. 1986, 51, 3007.

134. Kametani, T.; Ohtsuka, C.; Nemoto, H.; Fukumoto, K. Chem. Pharm. Bull. 1976, 24, 2525.

135. Kametani, T.; Yukawa, H.; Suzuki, Y.; Honda, T. J. Chem. Soc., Perkin Trans. 1 1985, 2151.

136. Kametani, T.; Nemoto, H. Tetrahedron 1981, 37, 3; Bijoy, P.; Naik, R. G.; Shivakumar, U.; Subba Rao, G. S. R. J. Indian Inst. Sci. 1994, 74, 519; Zeelen, F. J. Nat. Prod. Rep. 1994, 607.

137. Funk, R. L.; Vollhardt, K. P. C. J. Am. Chem. Soc. 1977, 99, 5483.

138. Kametani, T.; Nemoto, H.; Ishikawa, H.; Shiroyama, K.; Matsumoto, H.; Fukumoto, K. J. Am. Chem. Soc. 1977, 99, 3461.

139. Oppolzer, W.; Petrzilka, M.; Bättig, K. Helv. Chim. Acta 1977, 60, 2964.

140. Oppolzer, W.; Bättig, K.; Petrzilka, M. Helv. Chim. Acta 1978, 61, 1945.

141. For recent enantioselective synthesis of $(+)$ estrone see: Taber, D. F.; Raman, K.; Gaul, M. D. J. Org. Chem. 1987, $52,28$.

142. Grieco, P. A.; Takigawa, T.; Schillinger, W. J. J. Org. Chem. 1980, 45, 2247.

143. Sternberg, E. D.; Vollhardt, K. P. C. J. Org. Chem. 1982, 47, 3447.

144. Michellys, P.-Y.; Pellissier, H.; Santelli, M. Tetrahedron Lett. 1993, 34, 1931. 
145. Blazejewski, J.-C.; Haddad, M.; Wakselman, C. Tetrahedron Lett. 1994, 35, 2021.

146. Nemoto, H.; Matsuhashi, N.; Imaizumi, M.; Nagai, M.; Fukumoto, K. J. Org. Chem. 1990, 55, 5625.

147. Nemoto, H.; Satoh, A.; Fukumoto, K. J. Chem. Soc., Perkin Trans. 1 1994, 943.

148. Krohn, K. Angew. Chem., Int. Ed. Engl. 1986, 25, 790; Lown, J. W. Chem. Soc. Rev. 1993, 22, 165.

149. Kametani, T.; Takeshita, M.; Nemoto, H.; Fukumoto, K. Chem. Pharm. Bull. 1978, 26, 556.

150. Kerdesky, F. A. J.; Ardecky, R. J.; Lakshmikanthan, M. V.; Cava, M. P. J. Am. Chem. Soc. 1981, 103, 1992.

151. Swenton, J. S.; Anderson, D. K.; Jackson, D. K.; Narasimhan, L. J. Org. Chem. 1981, 46, 4825.

152. Azadi-Ardakani, M.; Hayes, R.; Wallace, T. W. Tetrahedron 1990, 46, 6851.

153. Jozefiak, T. H.; Almlöf, J. E.; Feyereisen, M. W.; Miller, L. L. J. Am. Chem. Soc. 1989, 111, 4105.

154. (a) Tago, T.; Minowa, T.; Okada, Y.; Nishimura, J. Tetrahedron Lett. 1993, 34, 8461; Gügel, A.; Kraus, A.; Spickermann, J.; Belik, P.; Müllen, K. Angew. Chem., Int. Ed. Engl. 1994, 33, 559. (b) For a review related to addition reactions of fullerene see: Hirsch, A. Synthesis 1995, 895; Iyoda, M.; Sultana, F.; Sasaki, S.; Yoshida, M. J. Chem. Soc., Chem. Commun. 1994, 1929; (c) Diederich, F.; Jonas, U.; Gramlich, V.; Herrmann, A.; Ringsdorf, H.; Thilgen, C. Helv. Chim. Acta 1993, 76, 2445; (d) Dominguez, O.; Echegoyen, L.; Cunha, F.; Tao, N. Langmuir 1998, 14, 821; (e) Zhang, X.; Foote, C. S. J. Org. Chem. 1994, 59, 5235; (f) Bidell, W.; Douthwaite, R. E.; Green, M. L. H.; Stephens, A. H. H.; Turner, J. F. C. J. Chem. Soc., Chem. Commun. 1994, 1641; (g) Herrera, A.; Martinez, R.; Gonzalez, B.; Illescas, B.; Martin, N.; Seoane, C. Tetrahedron Lett. 1997, 38, 4873; (h) Tomioka, H.; Yamamoto, K. J. Chem. Soc., Chem. Commun. 1995, 1961; Hoke II, S. H., Molstad, J.; Dilettato, D.; Jay, M. J.; Carlson, D.; Kahr, B.; Cooks, R. G. J. Org. Chem. 1992, 57, 5069; Ishida, T.; Shinozuka, K.; Nogami, T.; Sasaki, S.; Iyoda, M. Chem. Lett. 1995, 317.
155. Sekine, Y.; Boekelheide, V. J. Am. Chem. Soc. 1981, 103, 1777.

156. Sakurai, H.; Nakadaira, Y.; Hosomi, A.; Eriyama, Y. Chem. Lett. 1982, 1971.

157. Honda, T.; Ueda, K.; Tsubuki, M.; Toya, T.; Kurozumi, A. J. Chem. Soc., Perkin Trans. 1 1991, 1749.

158. Nemoto, H.; Suzuki, K.; Tsubuki, M.; Minemura, K.; Fukumoto, K.; Kametani, T.; Furuyama, H. Tetrahedron 1983, 39, 1123.

159. Cruciani, P.; Aubert, C.; Malacria, M. J. Org. Chem. 1995, 60, 2664; Cruciani, P.; Aubert, C.; Malacria, M. Synlett 1996, 105.

160. Stammler, R.; Halvorsen, K.; Gotteland, J.-P.; Malacria, M. Tetrahedron Lett. 1994, 35, 417; Phansavath, P.; Stammler, R.; Aubert, C.; Malacria, M. Synthesis 1998, 436.

161. Fukumoto, K.; Chihiro, M.; Ihara, M.; Kametani, T.; Honda, T. J. Chem. Soc., Perkin Trans. 1 1983, 2569.

162. Watabe, T.; Hosoda, Y.; Okada, K.; Oda, K. Bull. Chem. Soc. Jpn. 1987, 60, 3801.

163. Kotha, S.; Sreenivasachary, N.; Halder, S. Bioorg. Med. Chem. Lett. 1999, 9, 2565.

164. Kouno, I.; Komori, T.; Kawasaki, T. Tetradedron Lett. 1973, 46, 4569; Adinolfi, M.; Barone, G.; Belardini, M.; Lanzetta, R.; Laonigro, G.; Parrilli, M. Phytochemistry 1985, 24, 2423; Barone, G.; Corsaro, M. M.; Lanzetta, R.; Parrilli, M. Phytochemistry 1988, 27, 921; Adinolfi, M.; Barone, G.; Giordno, F.; Lanzetta, R.; Parrilli, M. Tetrahedron 1990, 46,6565 .

165. Honda, T.; Toya, T. Heterocycles 1992, 33, 291.

166. Rawal, V. H.; Cava, M. P. Tetrahedron Lett. 1983, 24, 5581.

167. WHO, Drug Information 1996, 10, 102.

168. Christophe, S.; Kuehm-Caubere, C.; Renard, P.; Pfeiffer, B.; Caubere, P. Tetrahedron Lett. 1998, 39, 9431.

169. Skorcz, J. A. US Patent 3,408,391; Chem. Abstr. 1969, 70, 47869a.

170. Jiang, T.; Rigney, J.; Jones, M.-C. G.; Markoski, L. J.; Spilman, G. E.; Mielewski, D. F.; Martin, D. C. Macromolecules 1995, 28, 3301. 


\section{Biographical Sketch}

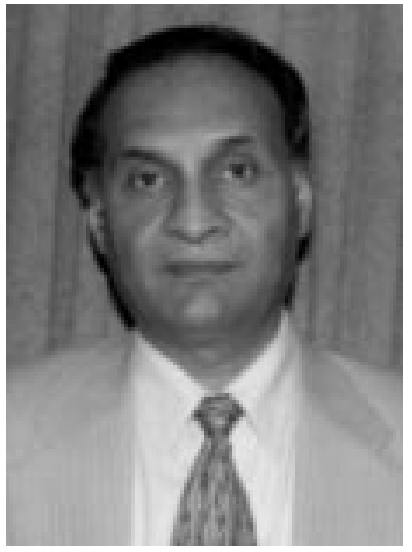

Goverdhan Mehta was born in Jodhpur, India and has held faculty positions at the Indian Institute of Technology, Kanpur and the University of Hyderabad. Currently he is a Professor of Organic Chemistry at the Indian Institute of Science, Bangalore. He has been a recipient of numerous awards and honors for his research accomplishments and has extensively lectured in India and abroad. Mehta's current research interest encompass total synthesis of natural products, design of aesthetically pleasing molecular entities, probing streoselective control of diastereoselectivity and photodynamic therapy of cancer.

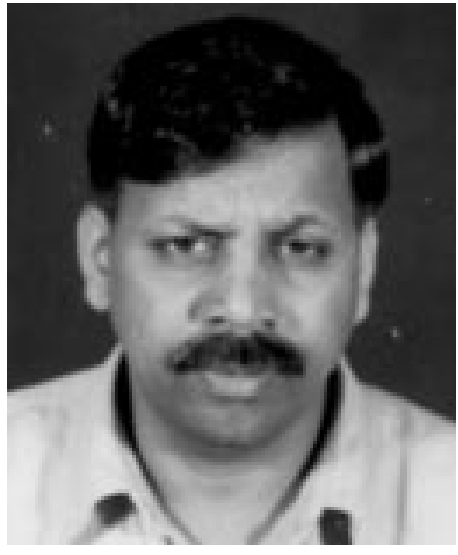

Sambasivarao Kotha was born in Amarthalur, Guntur district, AP, India. He received his BSc from Nagarjuna University in 1977 and MSc from University of Hyderabad in 1979. In 1985, he obtained his PhD under the supervision of Professor G. Mehta at University of Hyderabad. Subsequently, he worked with Professor R. J. Stoodley (1986-87) at UMIST, Manchester, UK, and Professor J. M. Cook (1987-89) at University of Wisconsin, Milwaukee as a research associate. Later on, he joined Cornell University as a visiting scientist and worked in Professor A. Kuki's group on AIB peptide synthesis. During 1992-93 he worked in Hoechst Celanese, TX as a Research Chemist-II. In 1994 he joined IIT-Bombay as an Assistant Professor and was promoted as an Associate Professor in 1997. He was a recipient of B. M. Birla prize in Chemical Sciences. His current research interests include methods in organic synthesis, unusual amino acids, peptide modifications, and theoretically interesting molecules. 